\title{
Design of NIR Chromenylium-Cyanine Fluorophore Library for "Switch-ON" and Ratiometric Detection of Bio-Active Species in Vivo
}

\author{
Yanfen Wei, Dan Cheng, Tianbing Ren, Yinhui Li, Zebing Zeng, Lin Yuan* \\ State Key Laboratory of Chemo/Biosensing and Chemometrics, College of Chemistry and \\ Chemical Engineering, Hunan University, Changsha 410082 (PR China)
}

\footnotetext{
* To whom correspondence should be addressed:

E-mail: lyuan@hnu.edu.cn
} 


\section{Table of content}

1. Supplemental Tables S1-3

S3-9

2. Supplemental Figures S9-23

S9-19

3. Synthesis and Characterization

S19-26

4. Supplemental NMR Spectra

S26-36 


\section{Supplemental Tables}

Table S1. Representative HPLC-MS dates of CC1-36.

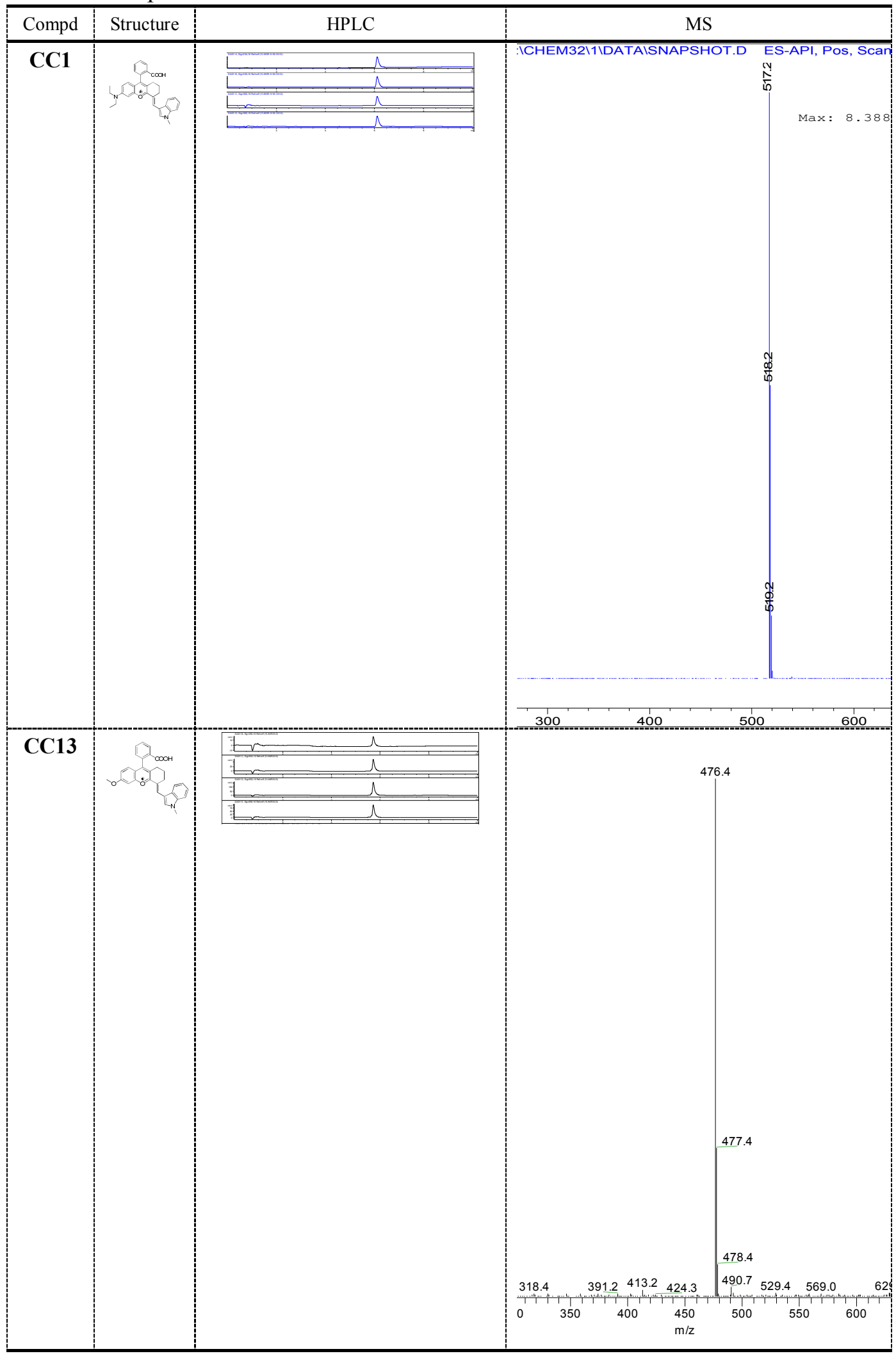




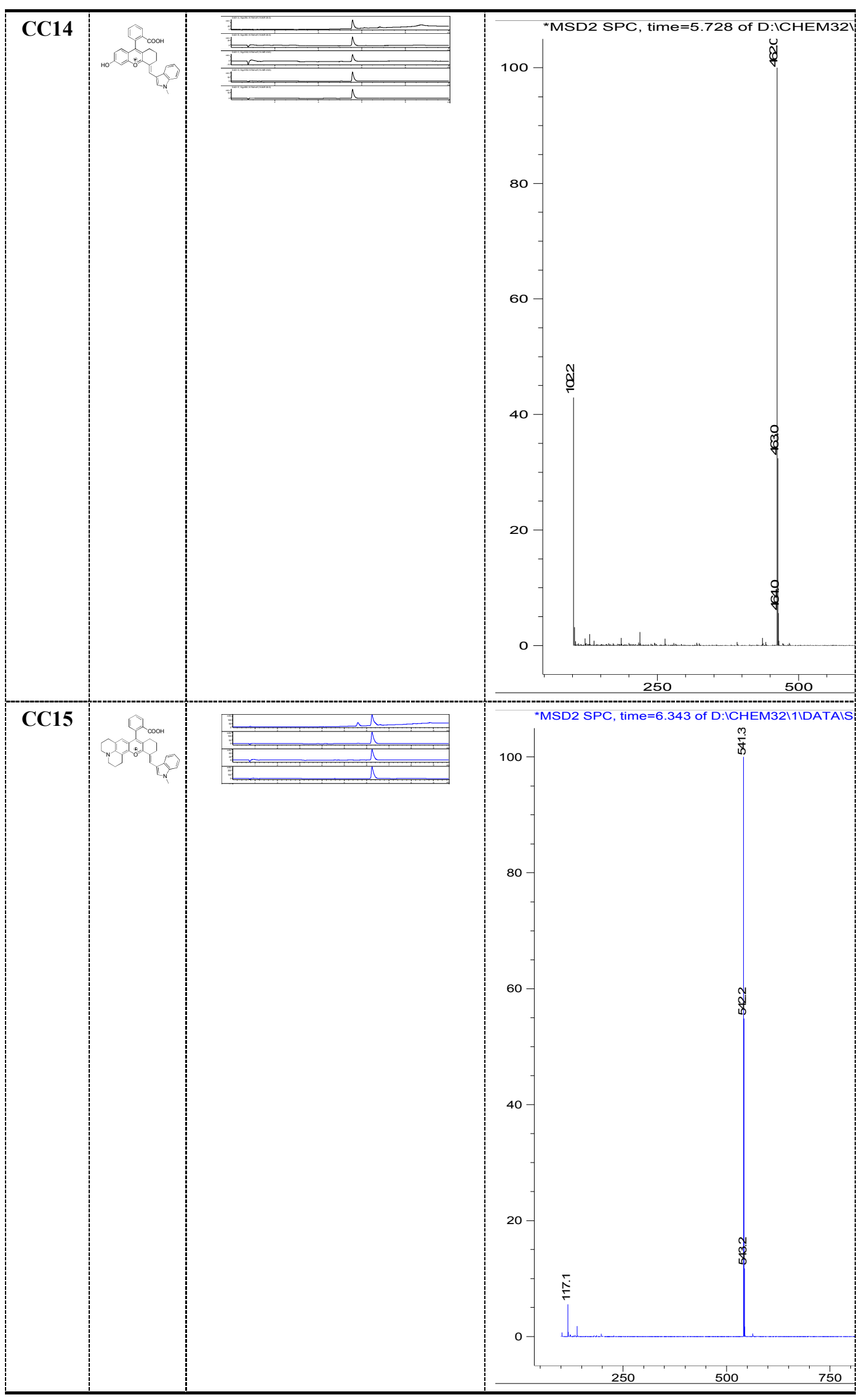




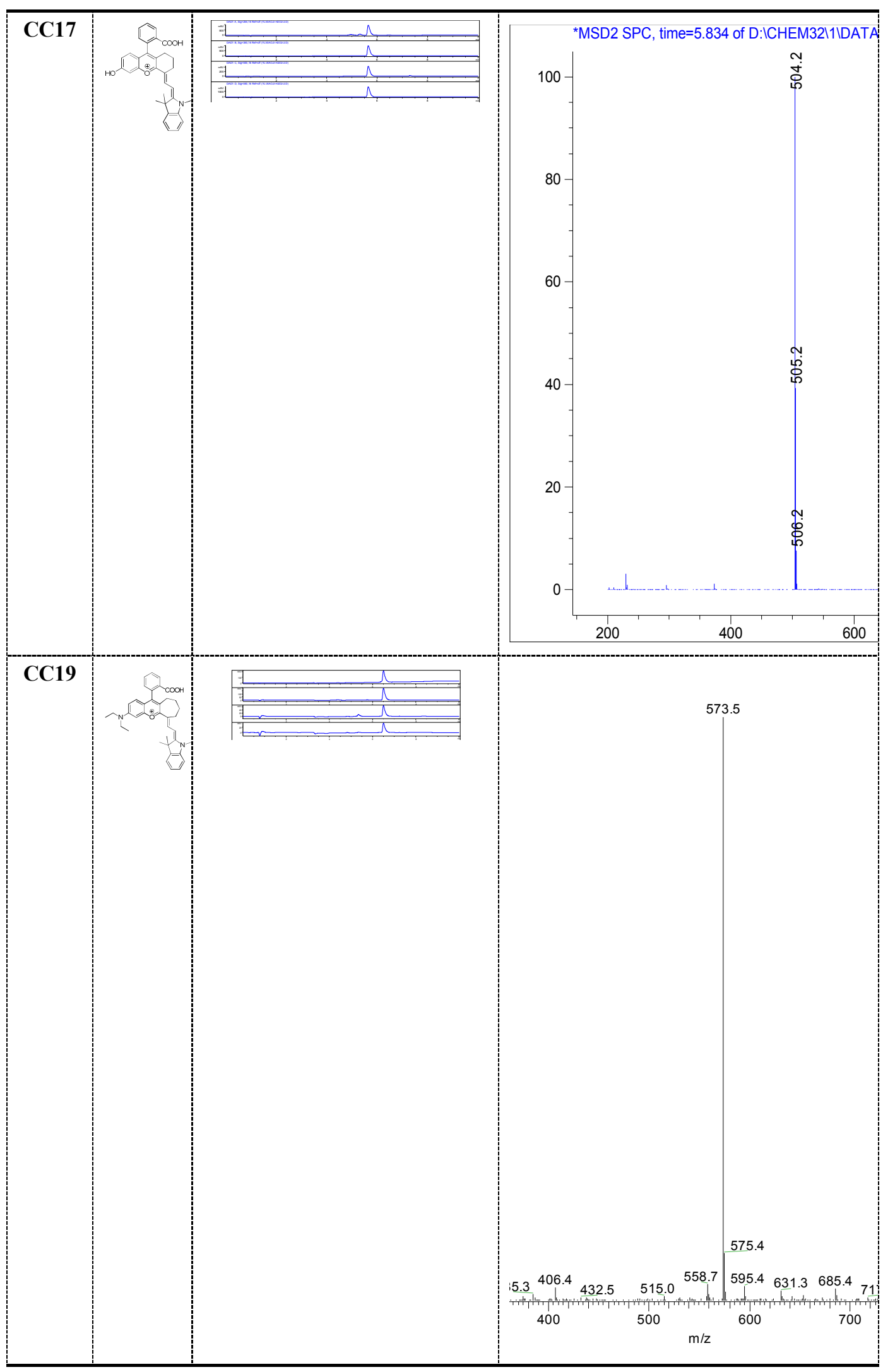




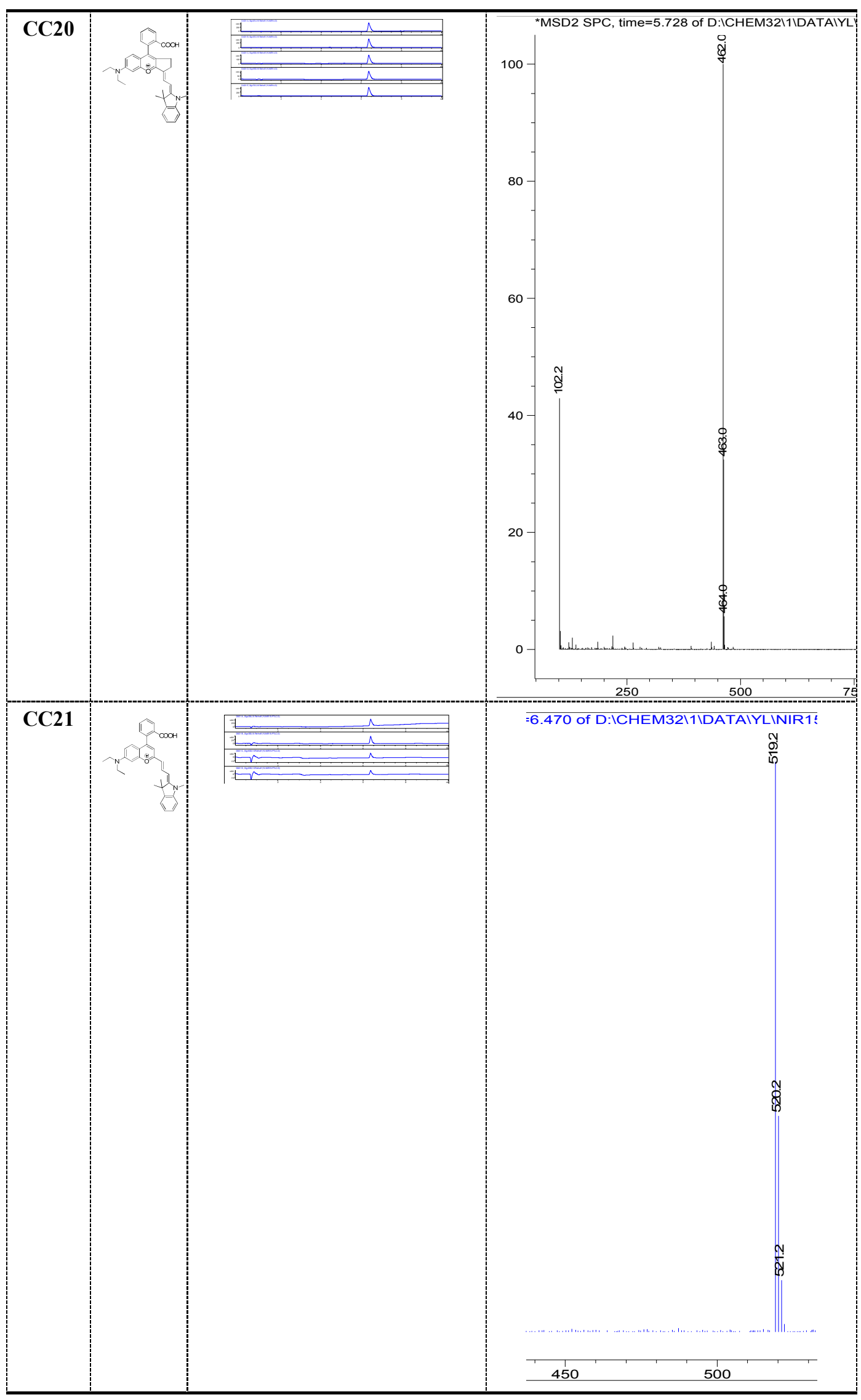




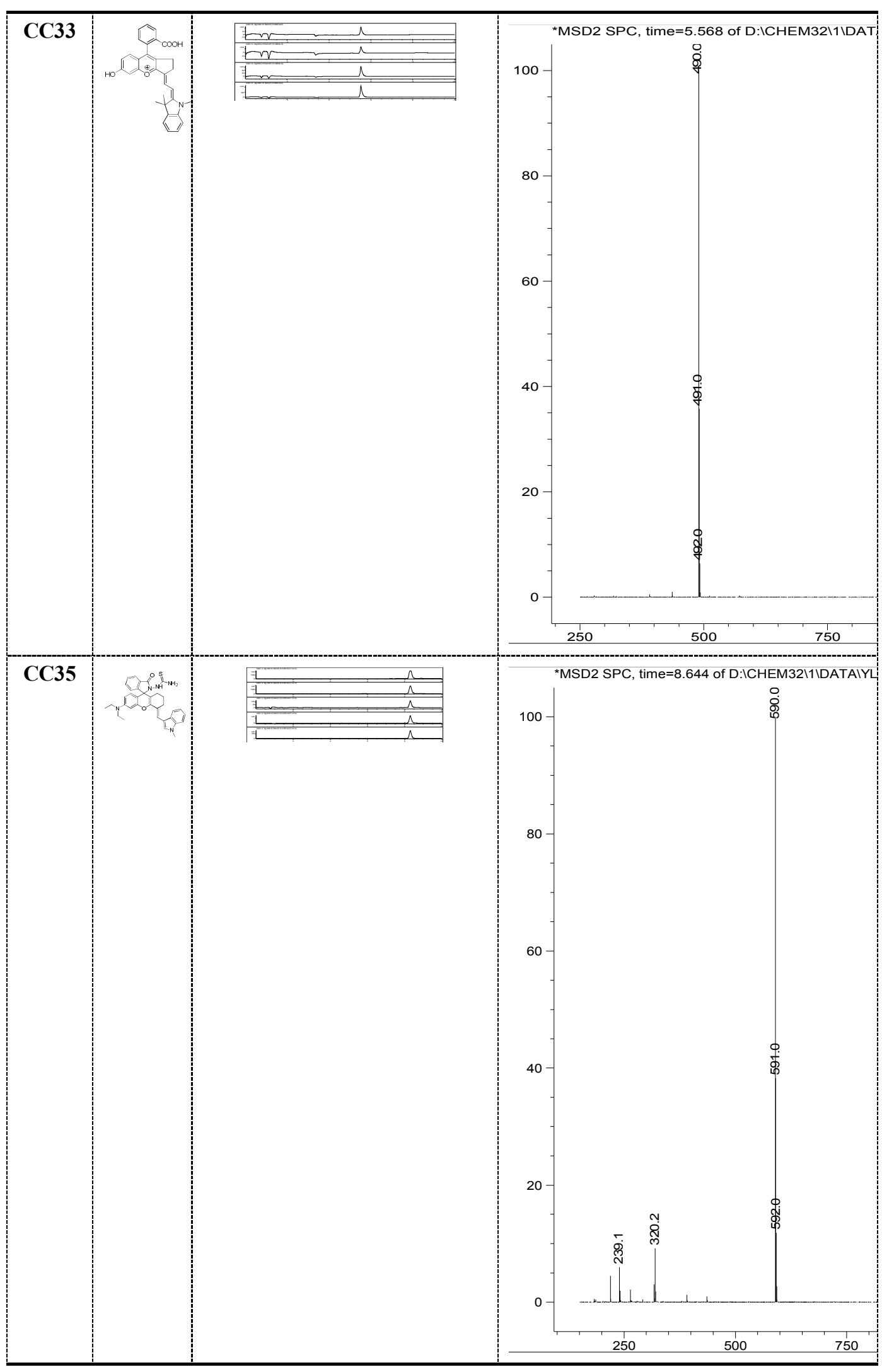




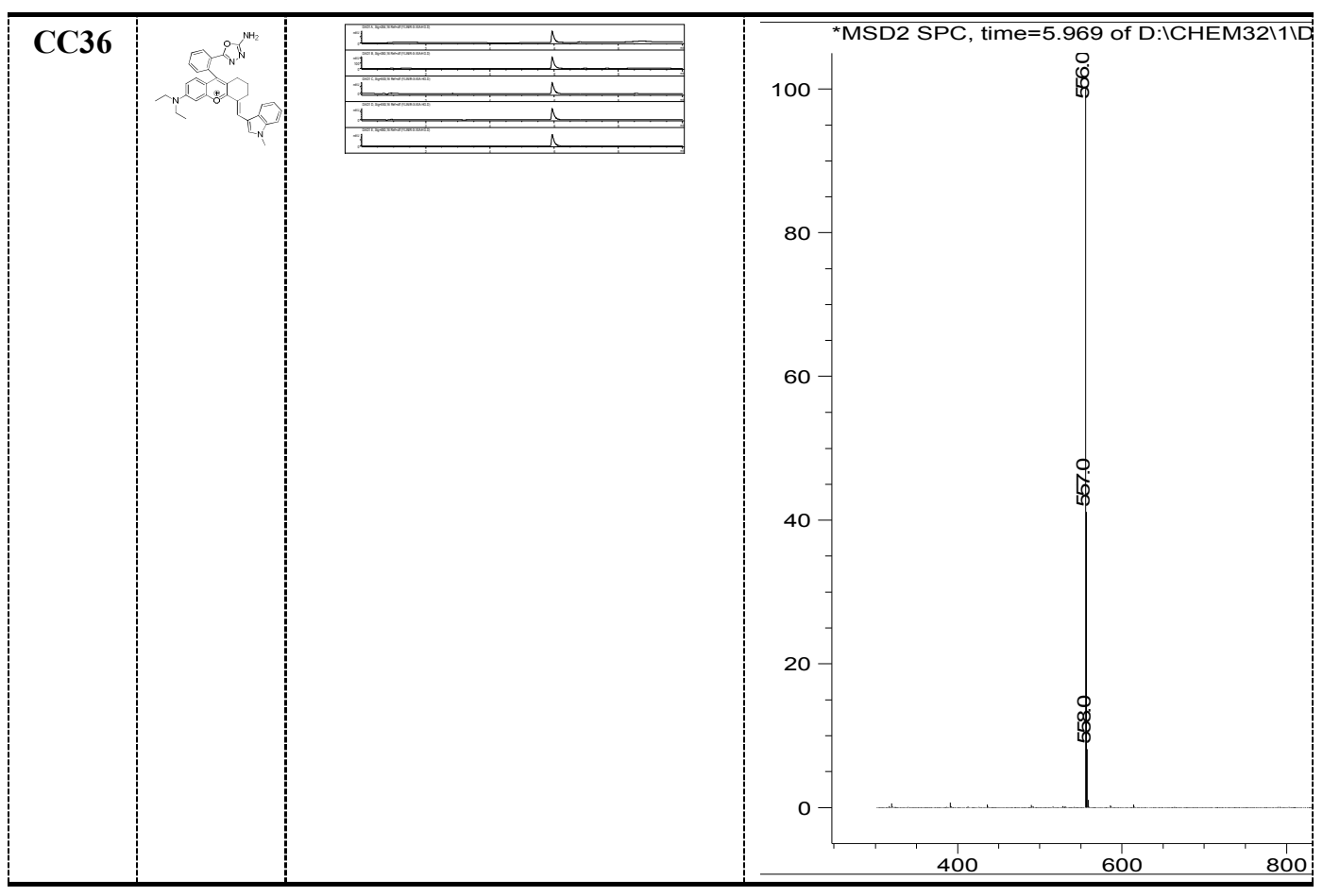

Table S2. Photo-physical properties of CC19-29 in EtOH.

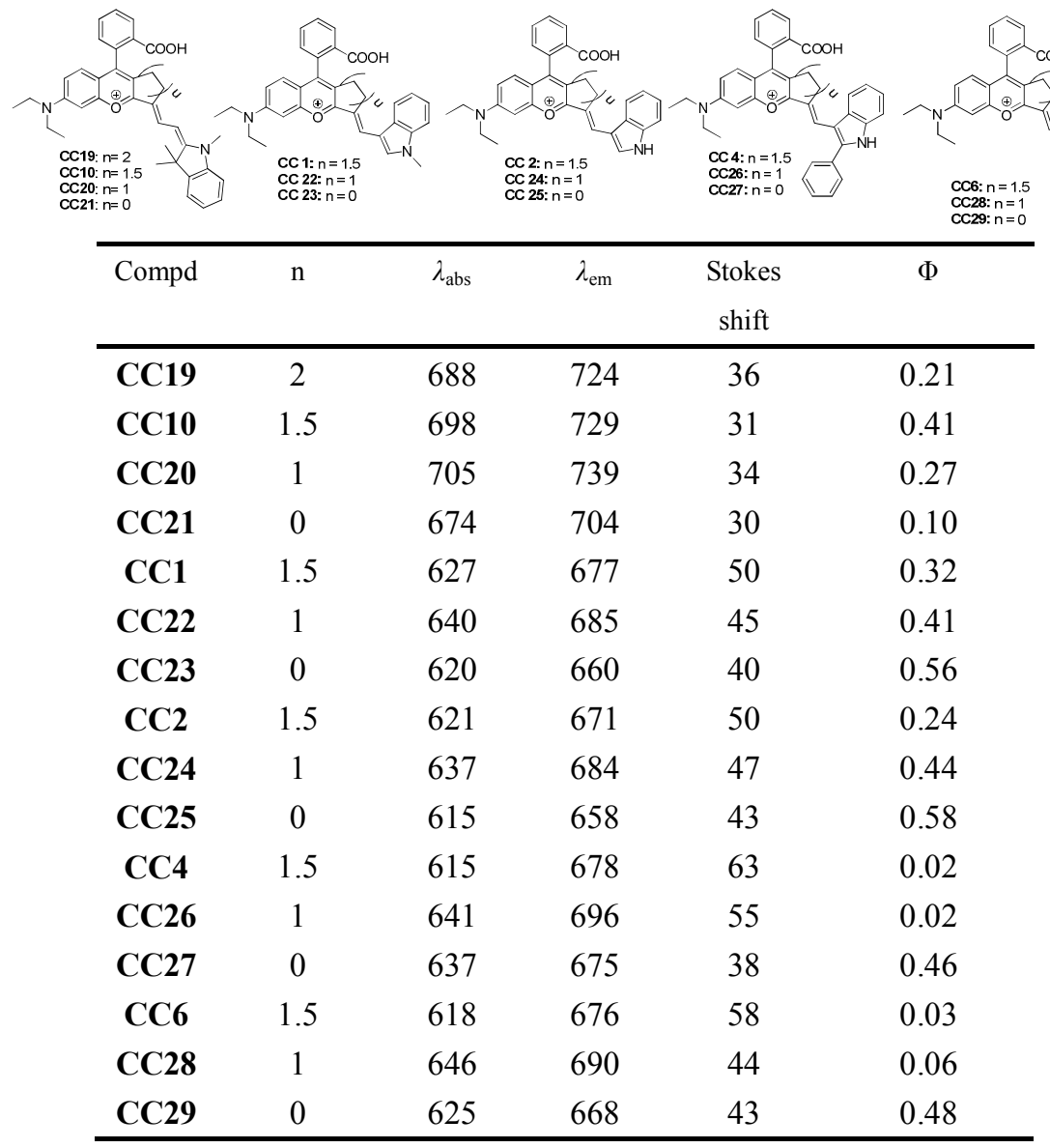


Table S3. Representative NIR fluorescent probes for $\mathrm{Hg}^{2+}$ based on organic fluorophore platforms for fluorescence imaging.

\begin{tabular}{|c|c|c|c|c|c|c|}
\hline Probe & $\begin{array}{c}\lambda_{\mathrm{ab}} / \lambda_{\mathrm{em}} \\
(\mathrm{nm})\end{array}$ & Medium & & $\begin{array}{l}\text { Detection } \\
\text { limit }\end{array}$ & $\begin{array}{l}\text { Imaging } \\
\text { application }\end{array}$ & Ref. \\
\hline R1 & $\begin{array}{c}630 / 69 \\
5\end{array}$ & $\begin{array}{c}\text { Tris- } \mathrm{HCl} / \mathrm{CH}_{3} \\
\mathrm{CN}(10 \mathrm{mM}, \\
\mathrm{pH} 7.4,1: 1, \\
\mathrm{v} / \mathrm{v})\end{array}$ & $\begin{array}{c}\text { Ratiometri } \\
\text { c }\end{array}$ & $\begin{array}{c}28 \mathrm{nM} \\
(S / N=3)\end{array}$ & HeLa cells & $\begin{array}{c}\text { Analyst, 2013, } \\
138,2654 .\end{array}$ \\
\hline B2 & $\begin{array}{c}370 / 65 \\
5\end{array}$ & $\begin{array}{l}\mathrm{CH}_{3} \mathrm{CN}-\mathrm{HEPE} \\
\mathrm{S} \text { buffer } \\
\text { solution }(10 \\
\mathrm{mM}, \mathrm{pH} \quad 7.4, \\
1: 1, \mathrm{v} / \mathrm{v})\end{array}$ & $\begin{array}{l}\text { 30-fold } \\
\text { fluorescen } \\
\text { ce } \\
\text { enhancem } \\
\text { ent }\end{array}$ & $\begin{array}{c}15 \mathrm{nM} \\
(S / N=3)\end{array}$ & HeLa cells & $\begin{array}{c}\text { J. Mater. Chem., } \\
\text { 2012, 22, } \\
11475 .\end{array}$ \\
\hline $\begin{array}{l}\text { SiR-H } \\
\quad \mathrm{g}\end{array}$ & $\begin{array}{c}664 / 68 \\
0\end{array}$ & $\begin{array}{c}\text { HEPES buffer } \\
\text { solution at } \mathrm{pH} \\
7.4\end{array}$ & $\begin{array}{c}\text { Fluorescen } \\
\text { ce } \\
\text { enhancem } \\
\text { ent }\end{array}$ & -- & $\begin{array}{l}\text { SH-SY5Y } \\
\text { cells }\end{array}$ & $\begin{array}{c}\text { Chem. } \\
\text { Commun., 2012, } \\
\text { 48, } 8781 .\end{array}$ \\
\hline and & $\begin{array}{l}672 \\
/ 690\end{array}$ & $\begin{array}{c}\mathrm{MeCN}-\mathrm{H}_{2} \mathrm{O} \\
(4: 1, \mathrm{v} / \mathrm{v} ; \mathrm{pH}= \\
7.2)\end{array}$ & Quenching & $5 \mu \mathrm{M}$ & $\begin{array}{l}\text { SMMC-772 } \\
1 \text { cells }\end{array}$ & $\begin{array}{c}\text { Chem. Lett. } \\
\mathbf{2 0 1 5}, \\
\text { doi:10.1246/cl.1 } \\
50240\end{array}$ \\
\hline $\begin{array}{c}\text { IR-89 } \\
7\end{array}$ & $\begin{array}{c}\text { Em: } \\
780 / 83 \\
0 \\
\end{array}$ & $\begin{array}{c}\text { Methanol/water } \\
(80: 20)\end{array}$ & $\begin{array}{l}\text { Ratiometri } \\
\text { c }\left(\mathrm{I}_{780}\right. \\
\left.\mathrm{nm} / \mathrm{I}_{830 \mathrm{~nm}}\right)\end{array}$ & $\begin{array}{c}--(\text { nanomol } \\
\text { ar level })\end{array}$ & -- & $\begin{array}{l}\text { Chem. Eur. J. } \\
\text { 2010, 16, } 14424\end{array}$ \\
\hline CC35 & $\begin{array}{c}670 / 70 \\
2\end{array}$ & $\begin{array}{l}\text { PBS buffer }(50 \\
\text { mM, pH } 7.4 \text {, } \\
\text { containing } 20 \% \\
\left.\mathrm{CH}_{3} \mathrm{OH}\right)\end{array}$ & $\begin{array}{l}\text { 105-fold } \\
\text { fluorescen } \\
\text { ce } \\
\text { enhancem } \\
\text { ent }\end{array}$ & $10 \mathrm{nM}$ & $\begin{array}{l}\text { Mouse } \\
\text { model }\end{array}$ & This Work \\
\hline
\end{tabular}




\section{Supplemental Figures}
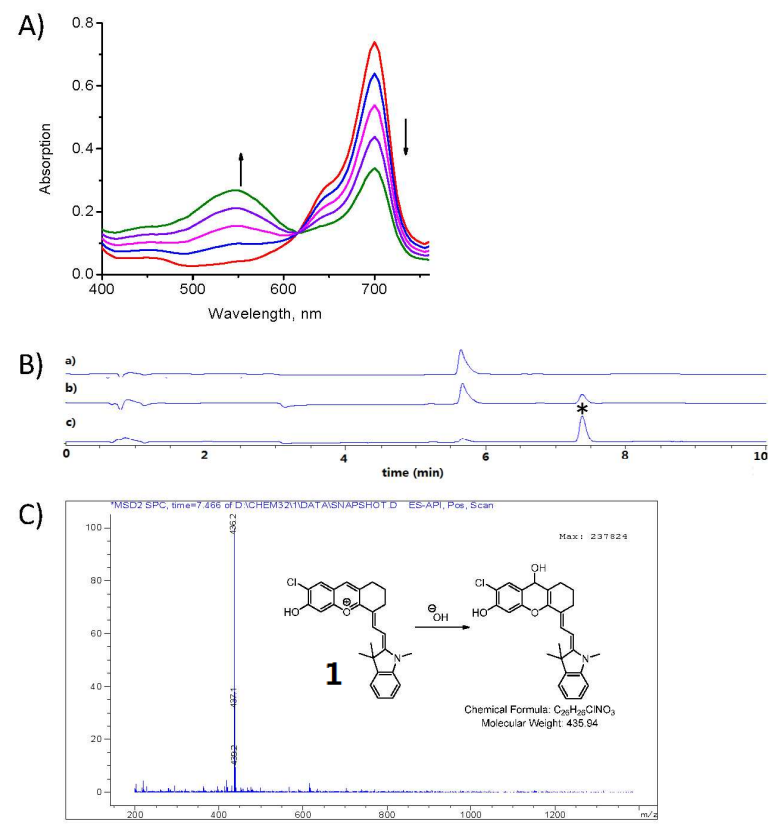

D)

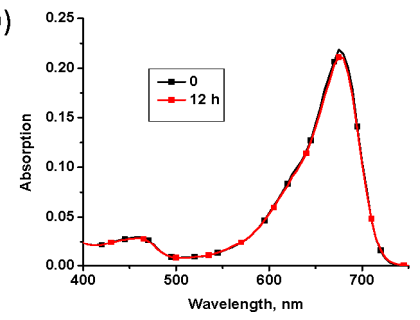

E)

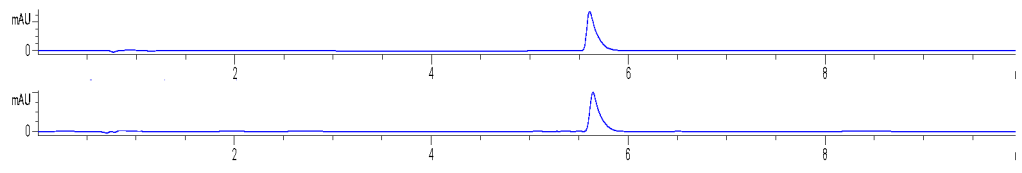

Figure S1. (A) Absorption spectra of compound 1 in water ( $\mathrm{pH} \mathrm{10)} \mathrm{for} \mathrm{0-12} \mathrm{hours.} \mathrm{(B)}$ HPLC chromatograms of dye 1 in water ( $\mathrm{pH} \mathrm{10)} \mathrm{for} 0$ (a), 2 hours (b) and 12 hours (c). The samples were analyzed by HPLC with linear gradient elution (eluent A $\left.\left(\mathrm{H}_{2} \mathrm{O}\right) / \mathrm{B}\left(\mathrm{CH}_{3} \mathrm{CN}\right)\right) 50 / 50,10 \mathrm{~min}, 0 / 100$; flow rate $\left.1.0 \mathrm{~mL} / \mathrm{min}\right)$. The monitored wavelength was $550 \mathrm{~nm}$. (C) The proposed fade mechanism of dye $\mathbf{1}$ in water and the mass spectra of 1-OH adduct. (D) Absorption spectra of compound CC17 in water (pH 10) for 0 and 12 hours. (E) HPLC chromatograms of dye CC17 in water (pH 10) for 0 (top), and 12 hours (bottom). 

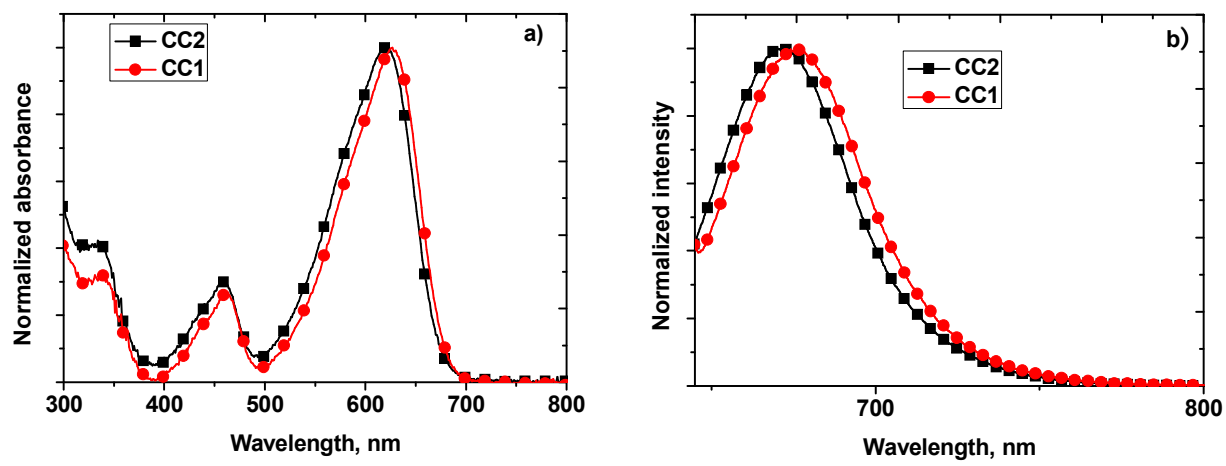

Figure S2. Normalized absorption (a) and emission (b) spectra of CC1 (•) and CC2 (a).
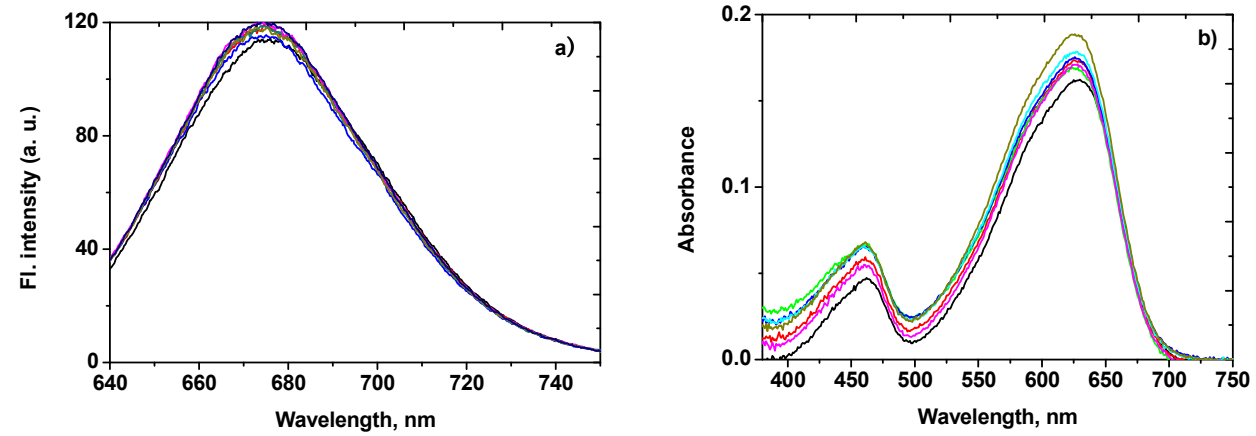

Figure S3. Emission (a) and absorption (b) spectra of CC2 in pH 4 to 10 in water (5\% DMF as co-solvent).

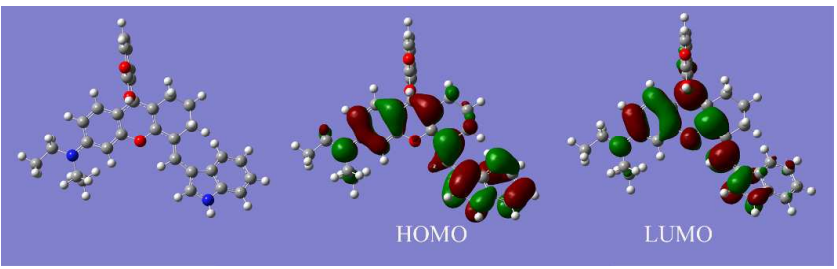

Figure S4. DFT optimized structure and molecular orbital plots (LUMO and HOMO) of CC 2. 


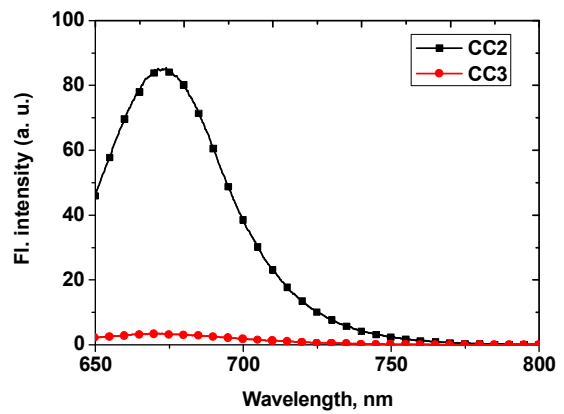

Figure S5. Emission spectra of CC3 (•) and CC2 (ロ).
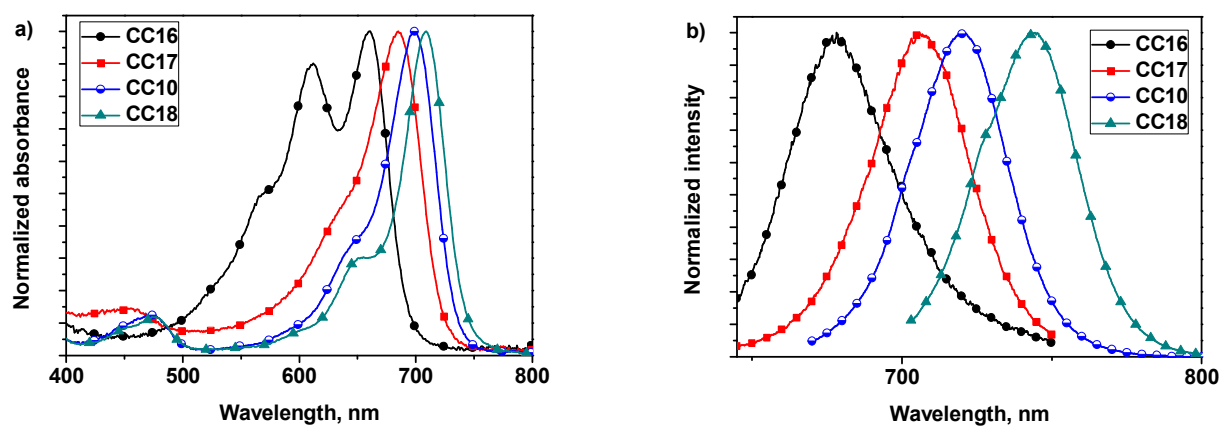

Figure S6. Normalized absorption (a) and emission (b) spectra of CC16-18 and CC10.

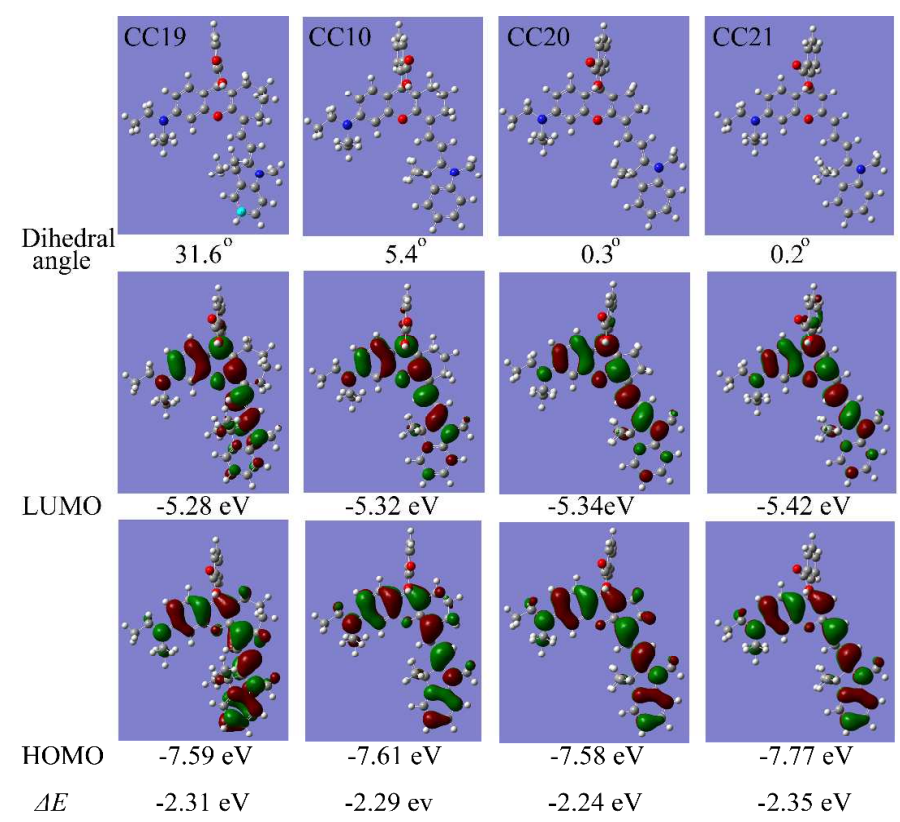

Figure S7. DFT optimized structure (including dihedral angle between chromenylium and indole moieties), molecular orbital plots (LUMO and HOMO) and HOMO/ LUMO energy gaps of CC19 - 21 and CC10. 

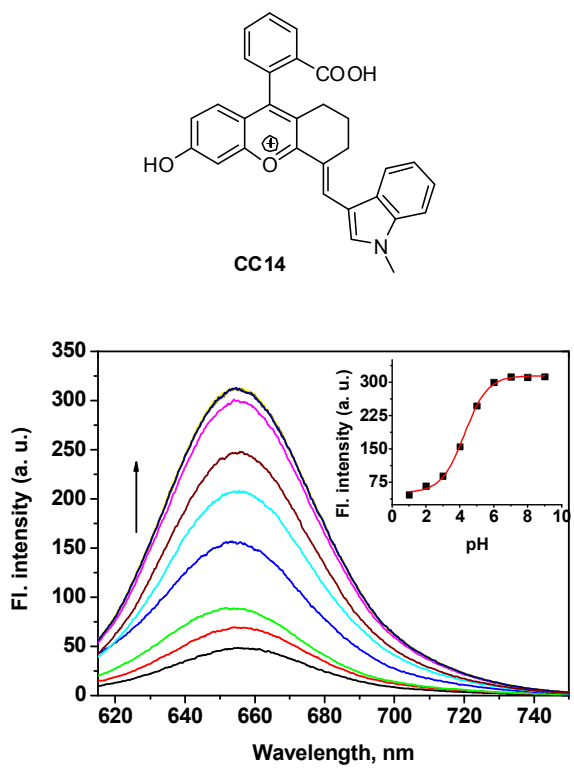

Figure S8. Fluorescence emission spectra of CC14 in buffer solution with $\mathrm{pH}$ changing from 1.0 to 9.0. Inset: $\mathrm{pH}$ plot of normalized emission intensities at $655 \mathrm{~nm}$ for CC14. Measurements were made in $50 \mathrm{mM}$ sodium phosphate buffer at various $\mathrm{pH}$ values in the presence of 5\% DMF as a cosolvent.
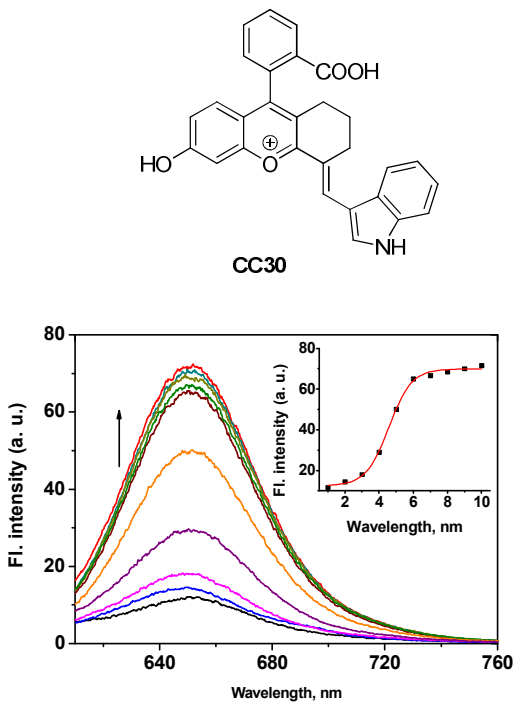

Figure S9. Fluorescence emission spectra of CC30 in buffer solution with $\mathrm{pH}$ changing from 1.0 to 10.0. Inset: $\mathrm{pH}$ plot of normalized emission intensities at $650 \mathrm{~nm}$ for CC30. Measurements were made in $50 \mathrm{mM}$ sodium phosphate buffer at various $\mathrm{pH}$ values in the presence of 5\% DMF as a cosolvent. 

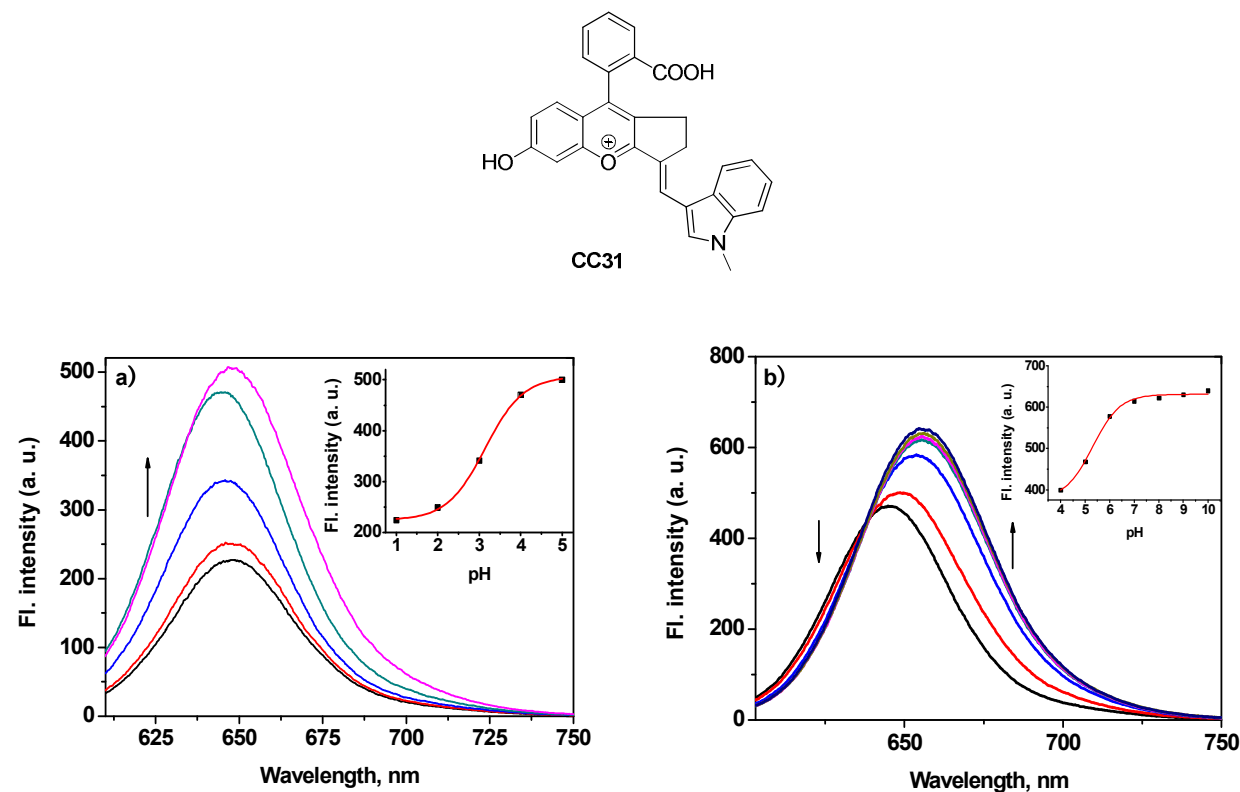

Figure S10. Fluorescence emission spectra of CC31 in buffer solution with $\mathrm{pH}$ changing from 1.0 to 5.0 (a) and 4.0 to 10.0 (b). Inset: $\mathrm{pH}$ plot of normalized emission intensities at $645 \mathrm{~nm}$ (a) or $656 \mathrm{~nm}$ (b). Measurements were made in $50 \mathrm{mM}$ sodium phosphate buffer at various $\mathrm{pH}$ values in the presence of 5\% DMF as a cosolvent.
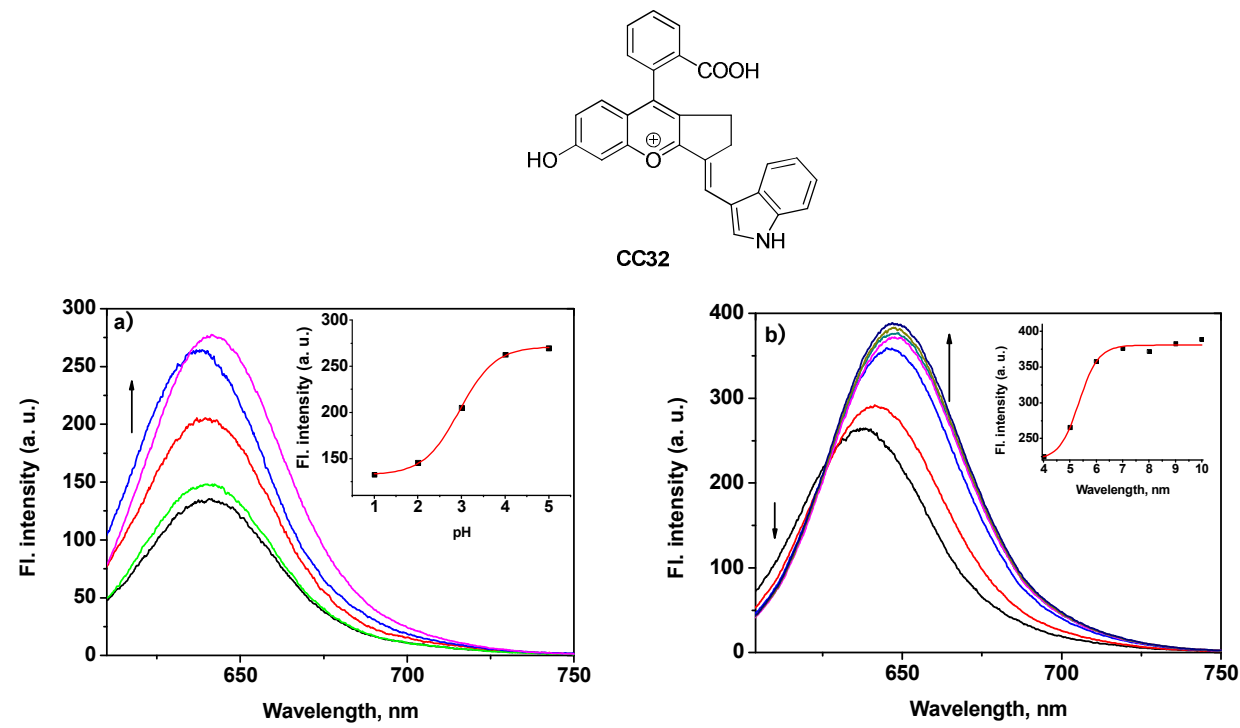

Figure S11. Fluorescence emission spectra of CC32 in buffer solution with $\mathrm{pH}$ changing from 1.0 to 5.0 (a) and 4.0 to 10.0 (b). Inset: $\mathrm{pH}$ plot of normalized emission intensities at $637 \mathrm{~nm}$ (a) or $648 \mathrm{~nm}$ (b). Measurements were made in $50 \mathrm{mM}$ sodium phosphate buffer at various $\mathrm{pH}$ values in the presence of 5\% DMF as a cosolvent. 


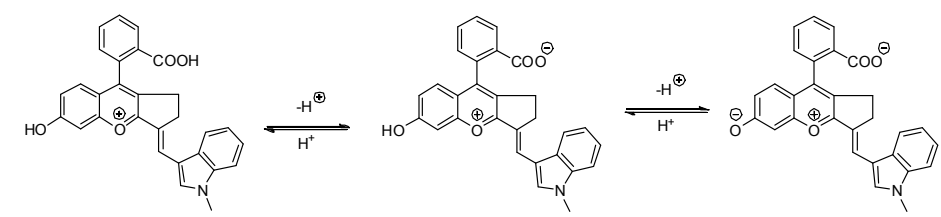

Figure S12. Estimated chemical equilibrium of CC31 in different $\mathrm{pH}$.
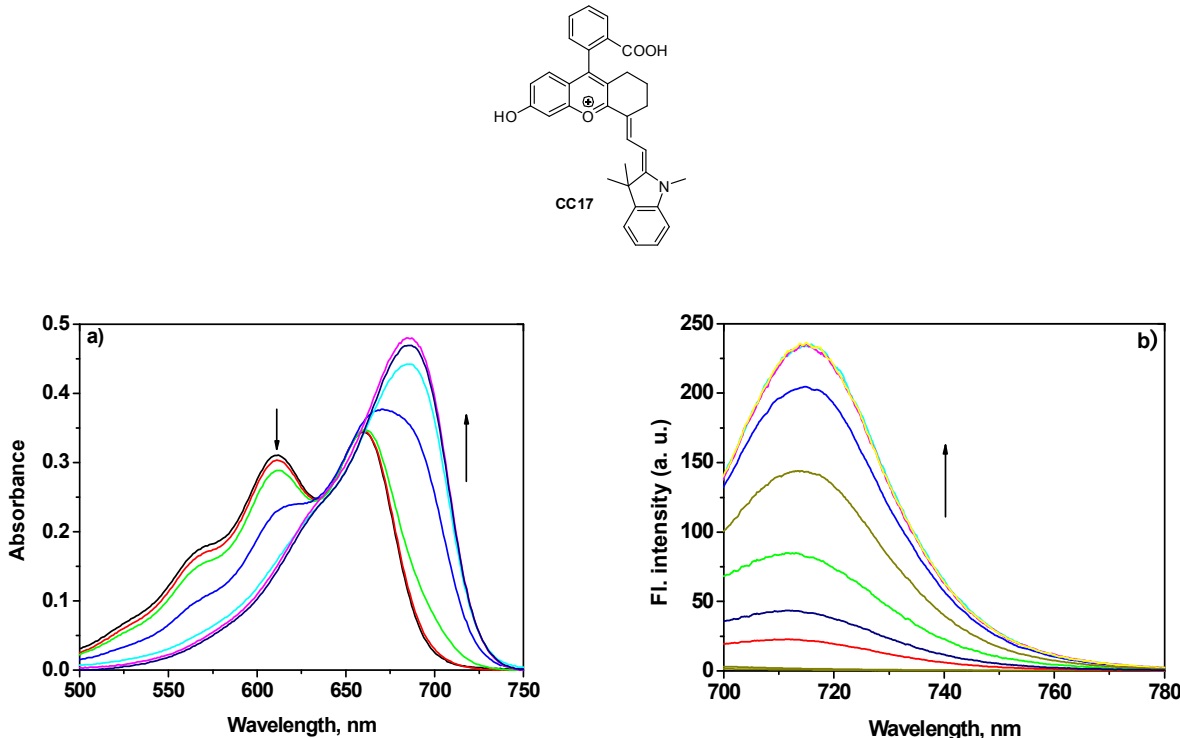

Figure S13. Absorption (a) and fluorescence emission (b) spectra of CC17 ( $\lambda_{\mathrm{ex}}=670$ $\mathrm{nm}$ ) in buffer solution with $\mathrm{pH}$ changing from 4.0 to 9.0. Measurements were made in $50 \mathrm{mM}$ sodium phosphate buffer at various $\mathrm{pH}$ values in the presence of $5 \% \mathrm{DMF}$ as a cosolvent.
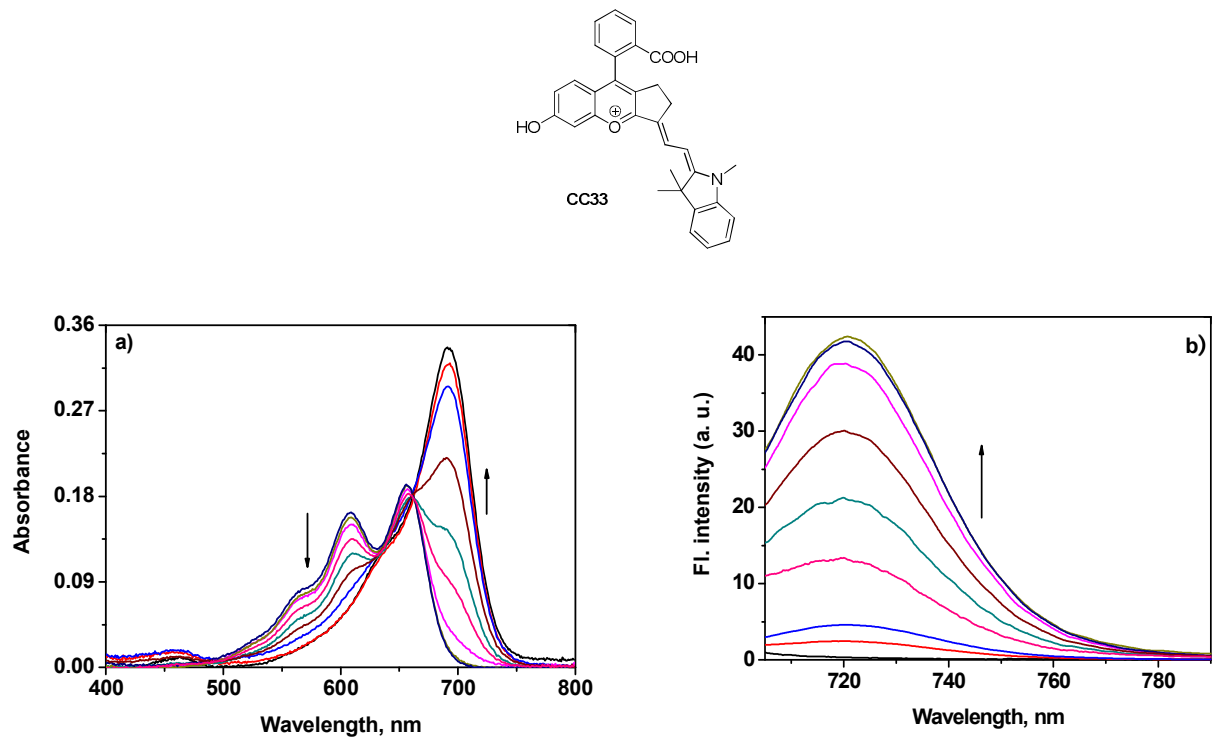

Figure S14. Absorption (a) and fluorescence emission (b) spectra of CC33 ( $\lambda_{\mathrm{ex}}=680$ $\mathrm{nm}$ ) in buffer solution with $\mathrm{pH}$ changing from 4.0 to 9.0. Measurements were made in $50 \mathrm{mM}$ sodium phosphate buffer at various $\mathrm{pH}$ values in the presence of 5\% DMF as a cosolvent. 

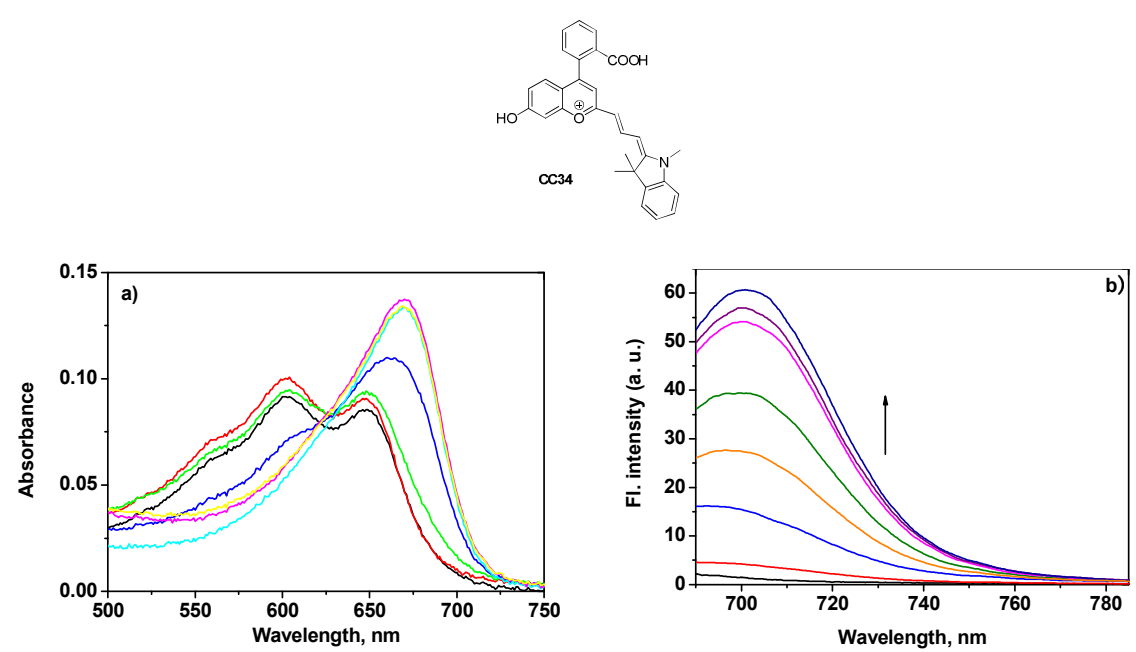

Figure S15. Absorption (a) and fluorescence emission (b) spectra of CC34 ( $\lambda_{\mathrm{ex}}=670$ $\mathrm{nm}$ ) in buffer solution with $\mathrm{pH}$ changing from 4.0 to 9.0. Measurements were made in $50 \mathrm{mM}$ sodium phosphate buffer at various $\mathrm{pH}$ values in the presence of 5\% DMF as a cosolvent.

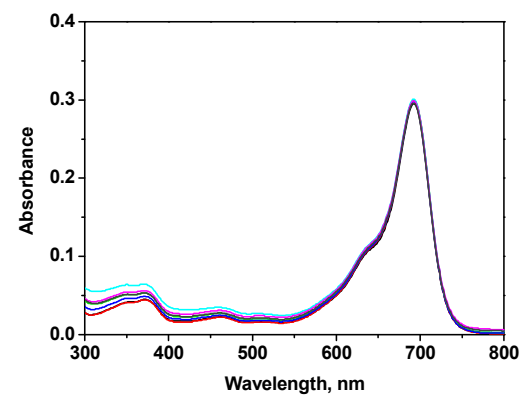

Figure S16. Absorption spectra of compound CC33 $(5 \mu \mathrm{M})$ in presence of intracellular nucleophilic reagent $\mathrm{H}_{2} \mathrm{~S}$ (5 equiv.) in water ( $\left.\mathrm{pH} 10\right)$ for 0 to 3 hours.

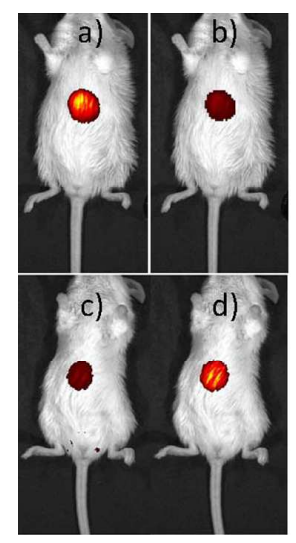

Figure S17. Representative fluorescence images of mice injected with CC33 in vivo. (a-b) PBS ( $\mathrm{pH}$ 5) was injected in the peritoneal cavity of mouse, followed by injection of CC33 $(60 \mu \mathrm{M})$. (c-d) PBS ( $\mathrm{pH} 8)$ was injected into the peritoneal cavity of the mouse, followed by injection of $\mathbf{C C 3 3}(60 \mu \mathrm{M})$. The mice were imaged with two emission channels of Channel 1 (650 nm, a, c) and Channel 2 (720 nm, b, d). 


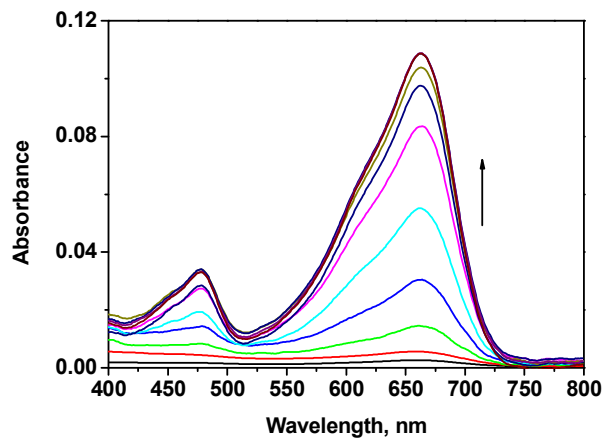

Figure S18. Absorption spectra of NIR fluorescent probe $\mathbf{C C 3 5}$ in the presence of various concentrations of $\mathrm{Hg}^{2+}(0-10 \mu \mathrm{M})$ in PBS buffer $(50 \mathrm{mM}, \mathrm{pH} 7.4$, containing $20 \% \mathrm{DMF})$.

a)

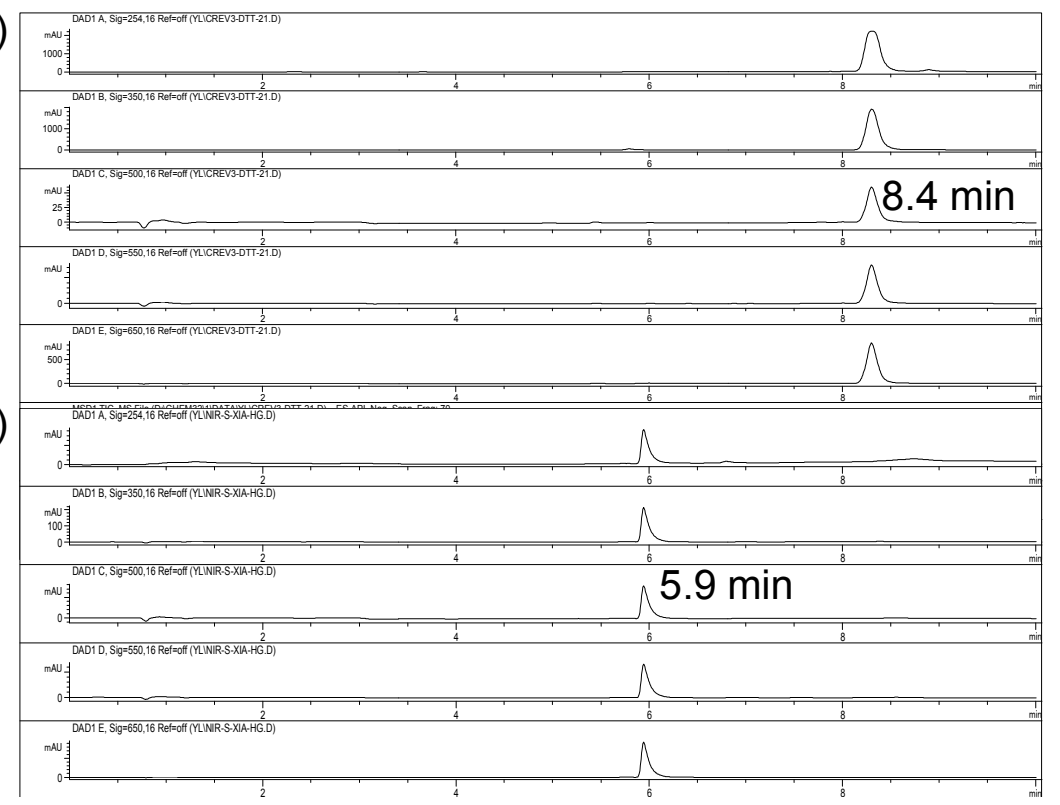

Figure S19. Reversed-phase HPLC with absorption (254, 350, 500, 550 and $650 \mathrm{~nm}$ ) detection. a) Reversed-phase HPLC of $50 \mu \mathrm{M}$ CC35. b) Reversed-phase HPLC of 50 $\mu \mathrm{M}$ CC35 in the presence of $100 \mu \mathrm{M} \mathrm{Hg}^{2+}$ for $1 \mathrm{~min}$. The ring-opened fluorescent dye CC36 was confirmed by Liquid chromatography-mass spectrometry (LC-MS) (Figure S20). 


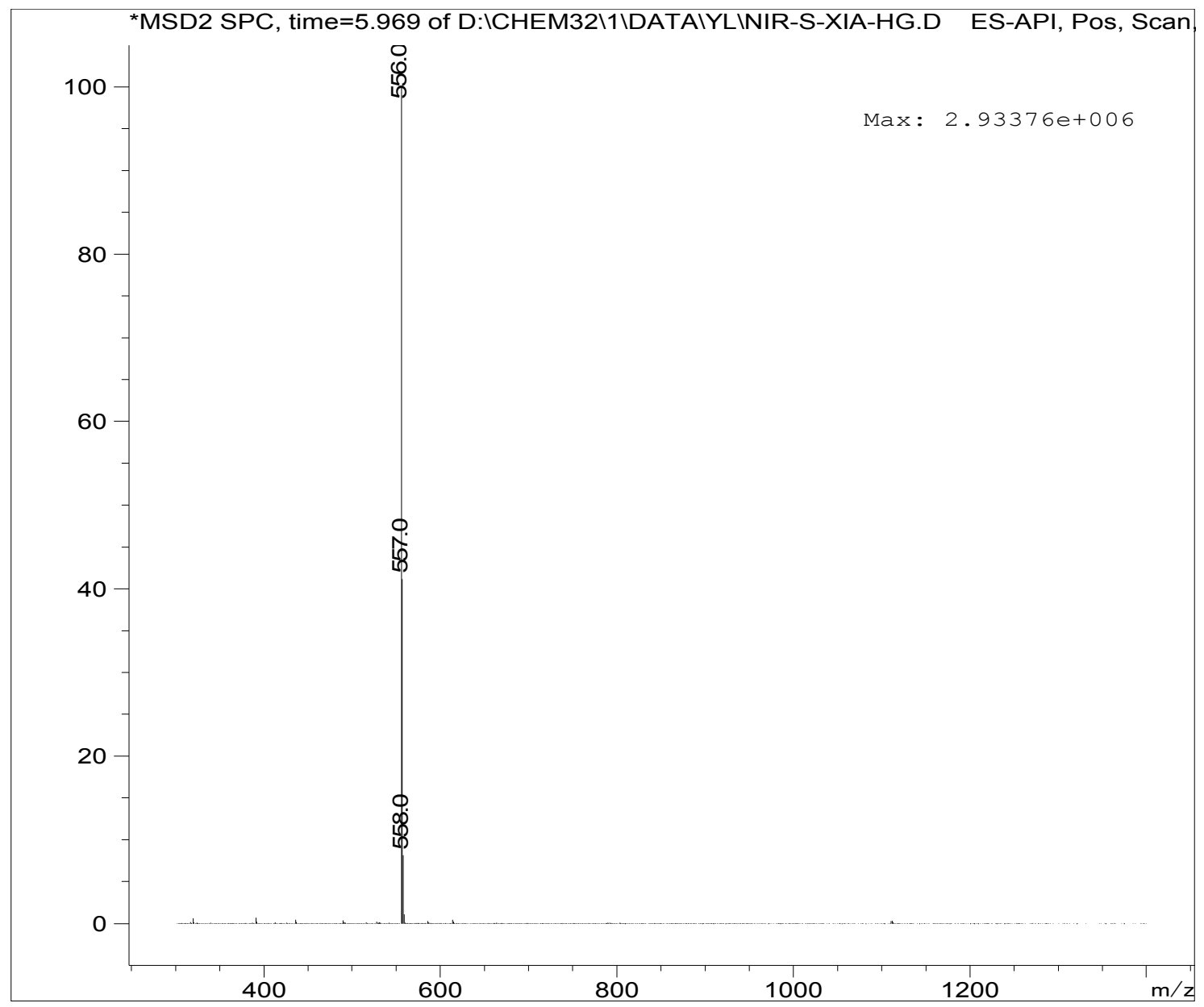

Figure S20. The mass spectrometry of $50 \mu \mathrm{M} \mathbf{C C 3 5}$ in the presence of $100 \mu \mathrm{M} \mathrm{Hg}^{2+}$ for $1 \mathrm{~min}$.

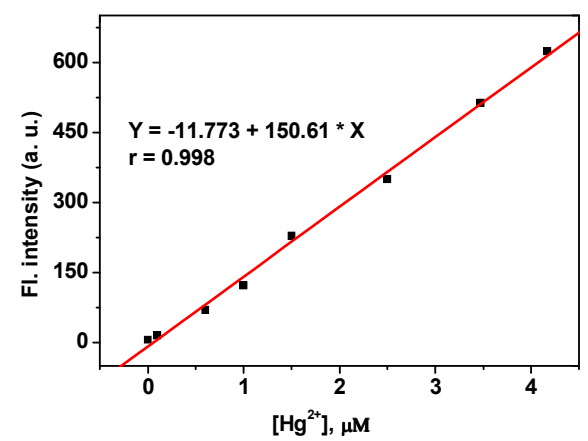

Figure S21. The fluorescence response of $\mathbf{C C 3 5}(5 \mu \mathrm{M})$ to $\mathrm{Hg}^{2+}(0.1 \mu \mathrm{M}-4 \mu \mathrm{M})$ in PBS buffer (50 mM, pH 7.4, containing 20\% DMF) with excitation at $670 \mathrm{~nm}$. 


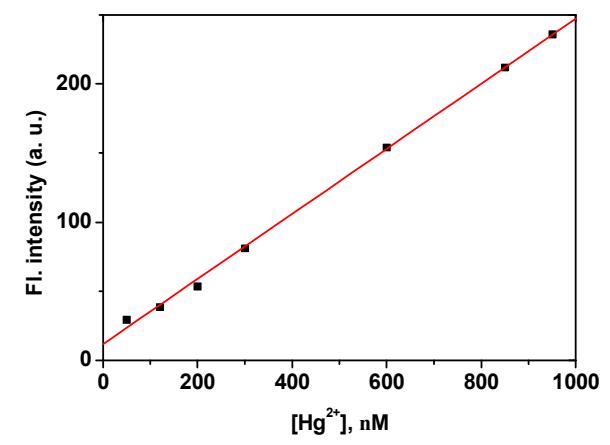

Figure S22. The fluorescence response of $\mathbf{C C 3 5}(1 \mu \mathrm{M})$ to $\mathrm{Hg}^{2+}(50 \mathrm{nM}-950 \mathrm{nM})$ in PBS buffer (50 mM, pH 7.4, containing 20\% DMF) with excitation at $670 \mathrm{~nm}$.

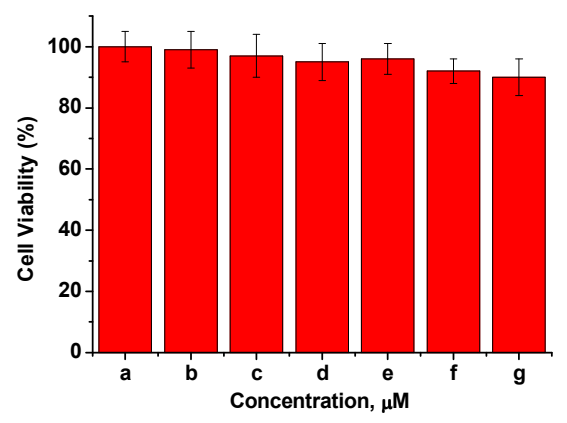

Figure S23. Cytotoxic effect of CC35. MCF-7 cells were incubated with each concentration (a: 0; b: $1 \mu \mathrm{M}$; c: $3 \mu \mathrm{M}$; d: $5 \mu \mathrm{M}$; e: $7 \mu \mathrm{M}$; f: $10 \mu \mathrm{M}$; g: $15 \mu \mathrm{M}$ ) of probes for $24 \mathrm{~h}$. Cell viability was assayed with MTT test. Results are expressed as mean \pm standard deviation of three independent experiments.

\section{Synthesis and Characterization}

Synthesis of CC1-34: CC8, CC10, CC12, and CC18 were synthesized according to reported procedure (J. Am. Chem. Soc. 2012, 134, 1200; Biomaterials 2015, 56, 1-9). Other compounds (CC1-34) were synthesized according to following procedure: A mixture of 4-(2-carboxyphenyl)-chromenylium derivatives $(0.22 \mathrm{mmol})$ and aldehyde $(0.24 \mathrm{mmol})$ was dissolved in ethanoyl ethanoate and then heated to 50 ${ }^{\circ} \mathrm{C}$ for 30 min to 5 hours until starting materials disappearing. After cooling, water (2 
$\mathrm{mL}$ ) was added to the mixture and the solvent was removed under reduced pressure. The resulting residue was purified by column chromatography on silica gel $\left(\mathrm{CH}_{2} \mathrm{Cl}_{2}\right.$ to $\mathrm{CH}_{2} \mathrm{Cl}_{2}$ /acetone =10: 1) to afford the compound $\mathbf{C C 1 - C C 3 4}$ as a solid.

CC1: Yield: 63\%. ${ }^{1} \mathrm{H}$ NMR (400 MHz, $d_{6}$-DMSO) $\delta 8.37$ (s, 1H), $8.21-8.08(\mathrm{~m}, 3 \mathrm{H})$, $7.85(\mathrm{t}, J=7.4 \mathrm{~Hz}, 1 \mathrm{H}), 7.74(\mathrm{t}, J=7.6 \mathrm{~Hz}, 1 \mathrm{H}), 7.61(\mathrm{~d}, J=7.8 \mathrm{~Hz}, 1 \mathrm{H}), 7.42-7.31$ (m, 3H), $7.25(\mathrm{~s}, 1 \mathrm{H}), 6.99(\mathrm{~s}, 1 \mathrm{H}), 6.78(\mathrm{~d}, J=9.0 \mathrm{~Hz}, 1 \mathrm{H}), 3.95(\mathrm{~s}, 3 \mathrm{H}), 3.59$ (q, $J=$ $6.9 \mathrm{~Hz}, 4 \mathrm{H}), 2.83(2 \mathrm{H}), 2.19(2 \mathrm{H}), 1.79(2 \mathrm{H}), 1.21(\mathrm{t}, J=6.9 \mathrm{~Hz}, 6 \mathrm{H}) .{ }^{13} \mathrm{C}$ NMR $(100$ MHz, $d_{6}$-DMSO) $\delta 167.75,159.86,150.54,137.05,133.99,130.46,128.52,123.54$, $121.51,119.66,112.88,111.10,100.12,99.85,96.60,45.14,33.85,28.03,25.40$, 21.11, 13.01. HRMS (m/z): $[\mathrm{M}]^{+}$calcd for $\left[\mathrm{C}_{34} \mathrm{H}_{33} \mathrm{~N}_{2} \mathrm{O}_{3}\right]^{+}$517.2486, found 517.2478.

CC2: Yield: 57\%. ${ }^{1} \mathrm{H}$ NMR (400 MHz, MeOD) $\delta 8.61$ (s, 1H), 8.19 (d, $J=7.2 \mathrm{~Hz}$, $1 \mathrm{H}), 8.12(\mathrm{~d}, J=8.5 \mathrm{~Hz}, 1 \mathrm{H}), 7.95(\mathrm{~s}, 1 \mathrm{H}), 7.71-7.66(2 \mathrm{H}), 7.47$ (d, $J=6.5 \mathrm{~Hz}, 1 \mathrm{H})$, $7.31-7.27(2 \mathrm{H}), 7.23$ (d, $J=4.3 \mathrm{~Hz}, 2 \mathrm{H}), 7.09$ (s, 2H), 3.68 (q, $J=6.9 \mathrm{~Hz}, 4 \mathrm{H}), 2.92$ $(2 \mathrm{H}), 2.03(2 \mathrm{H}), 1.92(2 \mathrm{H}), 1.32(\mathrm{t}, J=6.9 \mathrm{~Hz}, 6 \mathrm{H})$. HRMS (m/z): [M] $]^{+}$calcd for $\left[\mathrm{C}_{33} \mathrm{H}_{31} \mathrm{~N}_{2} \mathrm{O}_{3}\right]^{+}$503.2329, found 503.2318.

CC3: Yield: 53\%. ${ }^{1} \mathrm{H}$ NMR (400 MHz, $\left.\mathrm{CDCl}_{3}\right) \delta 8.45(\mathrm{~d}, J=7.3 \mathrm{~Hz}, 1 \mathrm{H}), 7.97(\mathrm{~d}, J=$ $7.6 \mathrm{~Hz}, 1 \mathrm{H}), 7.80$ (d, $J=7.4 \mathrm{~Hz}, 1 \mathrm{H}), 7.65$ (t, $J=7.4 \mathrm{~Hz}, 1 \mathrm{H}), 7.56$ (t, $J=7.5 \mathrm{~Hz}, 1 \mathrm{H}$ ), 7.46 (s, 2H), $7.44-7.38$ (m, 2H), 7.24 (d, $J=7.7 \mathrm{~Hz}, 1 \mathrm{H}), 6.52$ (d, $J=8.9 \mathrm{~Hz}, 1 \mathrm{H})$, 6.47 (s, 1H), 6.38 (d, $J=8.7 \mathrm{~Hz}, 1 \mathrm{H}), 3.38$ (q, $J=7.0 \mathrm{~Hz}, 4 \mathrm{H}), 2.69$ (s, 3H), 2.09 (t, $J$ $=6.4 \mathrm{~Hz}, 2 \mathrm{H}), 1.73-1.68(2 \mathrm{H}), 1.43(2 \mathrm{H}), 1.19(\mathrm{t}, J=7.0 \mathrm{~Hz}, 6 \mathrm{H})$. HRMS (m/z): $[\mathrm{M}]^{+}$calcd for $\left[\mathrm{C}_{35} \mathrm{H}_{33} \mathrm{~N}_{2} \mathrm{O}_{4}\right]^{+}$545.2435, found 545.2419.

CC4: Yield: 49\%. ${ }^{1} \mathrm{H}$ NMR (400 MHz, MeOD) $\delta 8.38$ (s, 1H), 8.26 (d, $J=7.7 \mathrm{~Hz}$, 1H), $7.77(\mathrm{t}, J=7.4 \mathrm{~Hz}, 1 \mathrm{H}), 7.73-7.66(\mathrm{~m}, 4 \mathrm{H}), 7.56-7.46(\mathrm{~m}, 4 \mathrm{H}), 7.30-7.24(\mathrm{~m}$, 2H), $7.21(\mathrm{~d}, J=7.5 \mathrm{~Hz}, 1 \mathrm{H}), 7.14(\mathrm{~d}, J=9.6 \mathrm{~Hz}, 1 \mathrm{H}), 7.07$ (d, $J=9.5 \mathrm{~Hz}, 1 \mathrm{H}), 7.01$ (s, 1H), $3.62(\mathrm{q}, J=6.9 \mathrm{~Hz}, 4 \mathrm{H}), 2.63(\mathrm{t}, J=5.6 \mathrm{~Hz}, 2 \mathrm{H}), 2.41(\mathrm{t}, J=5.6 \mathrm{~Hz}, 2 \mathrm{H})$, 1.73-1.69 (2H), $1.26(\mathrm{t}, J=6.9 \mathrm{~Hz}, 6 \mathrm{H}) .{ }^{13} \mathrm{C}$ NMR (100 MHz, MeOD) $\delta$ 163.20, 162.82 , 158.30, 155.06, 142.10, 137.05, 134.84, 133.38, 132.29, 132.16, 130.83, $129.66,129.56,128.73,128.63,128.46,127.31,125.84,122.94,122.58,121.48$, $120.71,120.26,116.66,116.49,113.29,111.64,110.53$, 95.09, 45.34, 29.35, 26.12, 22.33, 21.51, 11.38. HRMS (m/z): $[\mathrm{M}]^{+}$calcd for $\left[\mathrm{C}_{39} \mathrm{H}_{35} \mathrm{~N}_{2} \mathrm{O}_{3}\right]^{+}$579.2642, found 
579.2633.

CC5: Yield: $51 \% .{ }^{1} \mathrm{H}$ NMR (400 MHz, $\left.\mathrm{CDCl}_{3}\right) \delta 8.40(\mathrm{~s}, 1 \mathrm{H}), 8.22(\mathrm{~d}, J=5.9 \mathrm{~Hz}$, 1H), $7.78(\mathrm{~s}, 1 \mathrm{H}), 7.65$ (t, $J=7.0 \mathrm{~Hz}, 1 \mathrm{H}), 7.53(2 \mathrm{H}), 7.11(\mathrm{~d}, J=8.6 \mathrm{~Hz}, 1 \mathrm{H}), 7.06$ (2H), $6.93(\mathrm{~d}, J=8.6 \mathrm{~Hz}, 1 \mathrm{H}), 6.80(\mathrm{~d}, J=8.9 \mathrm{~Hz}, 1 \mathrm{H}), 6.74(\mathrm{~d}, J=8.5 \mathrm{~Hz}, 1 \mathrm{H}), 4.02$ (s, 3H), 3.59 (7H), $2.78(2 \mathrm{H}), 2.37-2.14(2 \mathrm{H}), 1.75(2 \mathrm{H}), 1.29$ (t, $J=6.9 \mathrm{~Hz}, 6 \mathrm{H})$. HRMS (m/z): $[\mathrm{M}]^{+}$calcd for $\left[\mathrm{C}_{35} \mathrm{H}_{35} \mathrm{~N}_{2} \mathrm{O}_{4}\right]^{+}$547.2591, found 547.2578.

CC6: Yield: 55\%. ${ }^{1} \mathrm{H}$ NMR (400 MHz, MeOD) $\delta 8.42(\mathrm{~s}, 1 \mathrm{H}), 8.28(\mathrm{~d}, J=7.8 \mathrm{~Hz}$, 1H), 7.80 (t, $J=7.4 \mathrm{~Hz}, 1 \mathrm{H}), 7.71(\mathrm{t}, J=7.5 \mathrm{~Hz}, 1 \mathrm{H}), 7.58$ (d, $J=7.5 \mathrm{~Hz}, 1 \mathrm{H}), 7.35$ (d, $J=7.3 \mathrm{~Hz}, 1 \mathrm{H}), 7.30$ (d, $J=7.5 \mathrm{~Hz}, 1 \mathrm{H}), 7.15$ (q, $J=7.3 \mathrm{~Hz}, 3 \mathrm{H}), 7.12-7.08$ (m, 1H), $7.03(\mathrm{~d}, J=9.5 \mathrm{~Hz}, 1 \mathrm{H}), 3.65$ (q, $J=6.9 \mathrm{~Hz}, 4 \mathrm{H}), 2.82$ (t, $J=5.5 \mathrm{~Hz}, 2 \mathrm{H}), 2.61$ (s, 3H), $2.44(\mathrm{t}, J=6.4 \mathrm{~Hz}, 2 \mathrm{H}), 1.80-1.70(\mathrm{~m}, 2 \mathrm{H}), 1.28$ (t, $J=6.9 \mathrm{~Hz}, 6 \mathrm{H})$. HRMS (m/z): $[\mathrm{M}]^{+}$calcd for $\left[\mathrm{C}_{34} \mathrm{H}_{33} \mathrm{~N}_{2} \mathrm{O}_{3}\right]^{+}$517.2486, found 517.2469.

CC7: Yield: 48\%. ${ }^{1} \mathrm{H}$ NMR (400 MHz, MeOD) $\delta 8.22$ (d, $\left.J=7.6 \mathrm{~Hz}, 1 \mathrm{H}\right), 8.17$ (s, 1H), $7.70-7.76(2 \mathrm{H}), 7.66(\mathrm{~d}, J=8.9 \mathrm{~Hz}, 2 \mathrm{H}), 7.24(\mathrm{~d}, J=7.4 \mathrm{~Hz}, 1 \mathrm{H}), 7.14(\mathrm{~s}, 1 \mathrm{H})$, $7.04-7.11(2 \mathrm{H}), 6.84(\mathrm{~d}, J=8.7 \mathrm{~Hz}, 2 \mathrm{H}), 3.66$ (q, $J=7.0 \mathrm{~Hz}, 4 \mathrm{H}), 3.10$ (s, 6H), 2.99 (t, $J=6.8 \mathrm{~Hz}, 2 \mathrm{H}), 2.42(\mathrm{t}, J=4.4 \mathrm{~Hz}, 2 \mathrm{H}), 1.88-1.80(\mathrm{~m}, 2 \mathrm{H}), 1.29(\mathrm{t}, J=7.0 \mathrm{~Hz}$, 6H). MS (ESI): $\mathrm{m} / \mathrm{z}=507.3[\mathrm{M}]+$. HRMS $(\mathrm{m} / \mathrm{z}):[\mathrm{M}]^{+}$calcd for $\left[\mathrm{C}_{33} \mathrm{H}_{35} \mathrm{~N}_{2} \mathrm{O}_{3}\right]^{+}$ 507.2642, found 507.2629.

CC9: Yield: 47\%. ${ }^{1} \mathrm{H}$ NMR $\left(400 \mathrm{MHz}, \mathrm{CDCl}_{3}\right) \delta 8.23(\mathrm{~d}, J=7.8 \mathrm{~Hz}, 1 \mathrm{H}), 7.99$ (s, $1 \mathrm{H}), 7.66(\mathrm{t}, J=7.4 \mathrm{~Hz}, 1 \mathrm{H}), 7.58(\mathrm{t}, J=7.6 \mathrm{~Hz}, 1 \mathrm{H}), 7.11(\mathrm{~d}, J=7.4 \mathrm{~Hz}, 1 \mathrm{H}), 7.01(\mathrm{~d}$, $J=1.9 \mathrm{~Hz}, 1 \mathrm{H}), 6.97(\mathrm{~s}, 1 \mathrm{H}), 6.86(\mathrm{~d}, J=9.4 \mathrm{~Hz}, 1 \mathrm{H}), 6.75(\mathrm{dd}, J=9.4,2.0 \mathrm{~Hz}, 1 \mathrm{H})$, $6.70(\mathrm{~d}, J=3.9 \mathrm{~Hz}, 1 \mathrm{H}), 6.34-6.29(\mathrm{~m}, 1 \mathrm{H}), 3.96(\mathrm{~s}, 3 \mathrm{H}), 3.58$ (q, $J=7.1 \mathrm{~Hz}, 4 \mathrm{H})$, $2.78(\mathrm{t}, J=4.9 \mathrm{~Hz}, 2 \mathrm{H}), 2.20(\mathrm{t}, J=7.6 \mathrm{~Hz}, 2 \mathrm{H}), 1.85-1.71(\mathrm{~m}, 2 \mathrm{H}), 1.27(\mathrm{t}, J=7.1$ $\mathrm{Hz}, 6 \mathrm{H}) . \mathrm{MS}(\mathrm{ESI}): \mathrm{m} / \mathrm{z}=467.2[\mathrm{M}]+\operatorname{HRMS}(\mathrm{m} / \mathrm{z}):[\mathrm{M}]^{+}$calcd for $\left[\mathrm{C}_{30} \mathrm{H}_{31} \mathrm{~N}_{2} \mathrm{O}_{3}\right]^{+}$ 467.2329, found 467.2335.

CC11: Yield: 50\%. ${ }^{1} \mathrm{H}$ NMR (400 MHz, MeOD) $\delta 8.69$ (s, 1H), 8.30 (d, $J=7.7 \mathrm{~Hz}$, $1 \mathrm{H}), 8.19(\mathrm{~d}, J=7.5 \mathrm{~Hz}, 1 \mathrm{H}), 8.12(\mathrm{~s}, 1 \mathrm{H}), 7.82(\mathrm{t}, J=7.2 \mathrm{~Hz}, 1 \mathrm{H}), 7.77-7.71(1 \mathrm{H})$, $7.47(\mathrm{~d}, J=7.5 \mathrm{~Hz}, 1 \mathrm{H}), 7.38-7.21(\mathrm{~m}, 9 \mathrm{H}), 7.12(\mathrm{~d}, J=9.4 \mathrm{~Hz}, 1 \mathrm{H}), 7.03$ (d, $J=$ $9.4 \mathrm{~Hz}, 1 \mathrm{H}), 5.56(\mathrm{~s}, 2 \mathrm{H}), 3.70(\mathrm{q}, J=13.8,6.9 \mathrm{~Hz}, 4 \mathrm{H}), 2.94$ (t, $J=5.7 \mathrm{~Hz}, 2 \mathrm{H}), 2.44$ $(\mathrm{t}, J=4.8 \mathrm{~Hz}, 2 \mathrm{H}), 2.06-2.02(\mathrm{~m}, 2 \mathrm{H}), 1.33(\mathrm{t}, J=6.9 \mathrm{~Hz}, 6 \mathrm{H}) . \operatorname{HRMS}(\mathrm{m} / \mathrm{z}):[\mathrm{M}]^{+}$ 
calcd for $\left[\mathrm{C}_{40} \mathrm{H}_{37} \mathrm{~N}_{2} \mathrm{O}_{3}\right]^{+}$593.2799, found 593.2783.

CC13: Yield: 63\%. ${ }^{1} \mathrm{H}$ NMR (400 MHz, $\left.\mathrm{CDCl}_{3}\right) \delta 7.97(\mathrm{~d}, J=7.3 \mathrm{~Hz}, 1 \mathrm{H}), 7.89(\mathrm{~d}, J$ $=7.6 \mathrm{~Hz}, 1 \mathrm{H}), 7.72(1 \mathrm{H}), 7.70(\mathrm{~d}, J=7.6 \mathrm{~Hz}, 1 \mathrm{H}), 7.62(\mathrm{~s}, 1 \mathrm{H}), 7.56(\mathrm{t}, J=7.5 \mathrm{~Hz}$, 1H), $7.53(1 \mathrm{H}), 7.37(\mathrm{t}, J=7.5 \mathrm{~Hz}, 1 \mathrm{H}), 7.29(\mathrm{t}, J=7.6 \mathrm{~Hz}, 1 \mathrm{H}), 7.22(1 \mathrm{H}), 6.82(\mathrm{~s}$, 1H), $6.61(\mathrm{~s}, 2 \mathrm{H}), 3.87(\mathrm{~s}, 3 \mathrm{H}), 3.85(\mathrm{~s}, 3 \mathrm{H}), 2.85(\mathrm{t}, 2 \mathrm{H}), 2.68(\mathrm{t}, 2 \mathrm{H}), 2.25-2.17(\mathrm{~m}$, 2H). HRMS (m/z): $[\mathrm{M}]^{+}$calcd for $\left[\mathrm{C}_{31} \mathrm{H}_{26} \mathrm{NO}_{4}\right]^{+}$476.1856, found 476.1848 .

CC14: Yield: $32 \% .{ }^{1} \mathrm{H}$ NMR (400 MHz, MeOD) $\delta 8.47$ (s, 1H), 8.15 (d, $J=6.5 \mathrm{~Hz}$, 1H), $7.90(\mathrm{~d}, J=7.1 \mathrm{~Hz}, 1 \mathrm{H}), 7.83(\mathrm{~s}, 1 \mathrm{H}), 7.59$ (d, $J=7.0 \mathrm{~Hz}, 1 \mathrm{H}), 7.54(\mathrm{~d}, J=7.5$ Hz, 1H), $7.40(\mathrm{~d}, J=7.6 \mathrm{~Hz}, 1 \mathrm{H}), 7.33-7.27(2 \mathrm{H}), 7.06(2 \mathrm{H}), 6.94(\mathrm{~d}, J=8.8 \mathrm{~Hz}$, $1 \mathrm{H}), 6.77(\mathrm{~d}, J=8.9 \mathrm{~Hz}, 1 \mathrm{H}), 3.87(\mathrm{~s}, 3 \mathrm{H}), 2.81(\mathrm{~s}, 2 \mathrm{H}), 2.44-2.36(\mathrm{~m}, 2 \mathrm{H}), 1.84(\mathrm{~s}$, 2H). HRMS (m/z): $[\mathrm{M}]^{+}$calcd for $\left[\mathrm{C}_{30} \mathrm{H}_{24} \mathrm{NO}_{4}\right]^{+}$472. 1700, found 462. 1716.

CC15: Yield: $50 \% .{ }^{1} \mathrm{H}$ NMR $\left(400 \mathrm{MHz}, \mathrm{CDCl}_{3}\right) \delta 8.26(\mathrm{~d}, J=4.4 \mathrm{~Hz}, 1 \mathrm{H}), 8.13(\mathrm{~s}$, 1H), $7.78(\mathrm{~d}, J=7.1 \mathrm{~Hz}, 1 \mathrm{H}), 7.62(\mathrm{~s}, 1 \mathrm{H}), 7.52(2 \mathrm{H}), 7.35(3 \mathrm{H}), 6.97(\mathrm{~d}, J=6.7 \mathrm{~Hz}$ 1H), $6.50(\mathrm{~s}, 1 \mathrm{H}), 3.90(\mathrm{~s}, 3 \mathrm{H}), 3.44(\mathrm{~d}, J=23.5 \mathrm{~Hz}, 4 \mathrm{H}), 3.07(2 \mathrm{H}), 2.80(2 \mathrm{H}), 2.60$ $(2 \mathrm{H}), 2.13(8 \mathrm{H})$. HRMS (m/z): $[\mathrm{M}]^{+}$calcd for $\left[\mathrm{C}_{36} \mathrm{H}_{33} \mathrm{~N}_{2} \mathrm{O}_{3}\right]^{+}$541.2486, found 541.2468

CC16: Yield: 56\%. ${ }^{1} \mathrm{H}$ NMR (400 MHz, MeOD) $\delta 8.72(\mathrm{~d}, J=14.6 \mathrm{~Hz}, 1 \mathrm{H}), 7.99$ (d, $J=7.3 \mathrm{~Hz}, 1 \mathrm{H}), 7.54-7.47(\mathrm{~m}, 3 \mathrm{H}), 7.41-7.34(\mathrm{~m}, 2 \mathrm{H}), 7.30(\mathrm{~d}, J=7.1 \mathrm{~Hz}, 1 \mathrm{H})$, $7.07(\mathrm{~d}, J=7.0 \mathrm{~Hz}, 1 \mathrm{H}), 6.99(\mathrm{~s}, 1 \mathrm{H}), 6.81(\mathrm{~d}, J=8.9 \mathrm{~Hz}, 1 \mathrm{H}), 6.75(\mathrm{~d}, J=8.9 \mathrm{~Hz}$, $1 \mathrm{H}), 6.29(\mathrm{~d}, J=14.7 \mathrm{~Hz}, 1 \mathrm{H}), 3.84(\mathrm{~s}, 3 \mathrm{H}), 3.68(\mathrm{~s}, 3 \mathrm{H}), 2.60(\mathrm{t}, J=5.6 \mathrm{~Hz}, 2 \mathrm{H})$, $2.34(\mathrm{t}, J=6.7 \mathrm{~Hz}, 2 \mathrm{H}), 1.78-1.73(8 \mathrm{H}) . \mathrm{MS}(\mathrm{ESI}): \mathrm{m} / \mathrm{z}=518.2[\mathrm{M}]^{+} . \mathrm{HRMS}(\mathrm{m} / \mathrm{z})$ : $[\mathrm{M}]^{+}$calcd for $\left[\mathrm{C}_{34} \mathrm{H}_{32} \mathrm{NO}_{4}\right]^{+}$518.2326, found 518.2319.

CC17: Yield: 44\%. ${ }^{1} \mathrm{H}$ NMR (400 MHz, $\mathrm{d}_{6}$-DMSO) $\delta 1.65-1.75(\mathrm{~m}, 2 \mathrm{H}), 1.78(\mathrm{~m}, 6 \mathrm{H})$, 2.18-2.22 (m, 1H), 2.29-2.34 (m, 1H), $2.66(1 \mathrm{H}), 3.85(\mathrm{~s}, 1 \mathrm{H}), 6.50(\mathrm{~d}, J=14.2 \mathrm{~Hz}$, $1 \mathrm{H}), 6.01(\mathrm{~d}, J=8.4 \mathrm{~Hz}, 1 \mathrm{H}), 6.76(\mathrm{dd}, J=8.6,2.2 \mathrm{~Hz}, 1 \mathrm{H}), 7.00(\mathrm{~d}, J=2.0 \mathrm{~Hz}, 1 \mathrm{H})$, $7.32(\mathrm{~d}, J=7.2 \mathrm{~Hz}, 1 \mathrm{H}), 7.44(\mathrm{t}, J=7.4 \mathrm{~Hz}, 1 \mathrm{H}), 7.53$ (t, $J=7.6 \mathrm{~Hz}, 1 \mathrm{H}), 7.63$ (d, $J=$ $8.0 \mathrm{~Hz}, 1 \mathrm{H}), 7.68(\mathrm{t}, J=7.4 \mathrm{~Hz}, 1 \mathrm{H}), 7.75(\mathrm{~d}, J=7.2 \mathrm{~Hz}, 1 \mathrm{H}), 7.80(\mathrm{t}, J=7.2 \mathrm{~Hz}, 1 \mathrm{H})$, $8.14(\mathrm{~d}, J=7.6 \mathrm{~Hz}, 1 \mathrm{H}), 8.66(\mathrm{~d}, J=14.0 \mathrm{~Hz}, 1 \mathrm{H}), 10.79$ (s, 1H, $-\mathrm{OH}), 12.97(\mathrm{~s}, 1 \mathrm{H}$, -COOH $).{ }^{13} \mathrm{C}$ NMR (100 MHz, $\mathrm{d}_{6}$-DMSO) 20.09, 23.63, 26.83, 27.68, 32.53, 50.23, $102.16,103.81,112.96,114.22,114.78,115.48,122.59,126.81,127.64,128.94$, 
$129.54,129.87,130.60,130.96,133.12,135.46,141.93,142.63,144.54,147.37$, 153.73, 160.86, 161.65, 166.91, 177.08. MS (ESI) 504.2. HRMS (m/z): [M] $]^{+}$calcd for $\left[\mathrm{C}_{33} \mathrm{H}_{30} \mathrm{NO}_{4}\right]^{+}$504.2169, found 504.2156.

CC19: Yield: $31 \% .{ }^{1} \mathrm{H}$ NMR $\left(400 \mathrm{MHz}, \mathrm{CDCl}_{3}\right) \delta 8.35(\mathrm{~d}, J=13.7 \mathrm{~Hz}, 1 \mathrm{H}), 8.26(\mathrm{~d}$, $J=7.6 \mathrm{~Hz}, 1 \mathrm{H}), 7.61(\mathrm{t}, J=7.3 \mathrm{~Hz}, 1 \mathrm{H}), 7.53(\mathrm{t}, J=7.4 \mathrm{~Hz}, 1 \mathrm{H}), 7.33(2 \mathrm{H}), 7.14(\mathrm{t}, J$ $=7.3 \mathrm{~Hz}, 1 \mathrm{H}), 7.08(\mathrm{~d}, J=7.4 \mathrm{~Hz}, 1 \mathrm{H}), 7.01(\mathrm{~d}, J=7.7 \mathrm{~Hz}, 1 \mathrm{H}), 6.77$ (d, $J=9.2 \mathrm{~Hz}$, 1H), 6.65 (d, $J=9.2 \mathrm{~Hz}, 1 \mathrm{H}), 6.55(\mathrm{~s}, 1 \mathrm{H}), 5.92$ (d, $J=13.4 \mathrm{~Hz}, 1 \mathrm{H}), 3.58-3.45(7 \mathrm{H})$, $2.72(\mathrm{~s}, 2 \mathrm{H}), 2.53-2.36(2 \mathrm{H}), 2.04(2 \mathrm{H}), 1.89(2 \mathrm{H}), 1.75(\mathrm{~s}, 6 \mathrm{H}), 1.26(\mathrm{t}, J=6.6 \mathrm{~Hz}$, 6H). MS (ESI): $\mathrm{m} / \mathrm{z}=573.5[\mathrm{M}]+$.

CC20: Yield: 53\%. ${ }^{1} \mathrm{H}$ NMR (400 MHz, MeOD) $\delta 8.24(\mathrm{t}, J=10.2 \mathrm{~Hz}, 2 \mathrm{H}), 7.78(\mathrm{t}, J$ $=7.5 \mathrm{~Hz}, 1 \mathrm{H}), 7.67(\mathrm{t}, J=7.6 \mathrm{~Hz}, 1 \mathrm{H}), 7.53(\mathrm{~d}, J=7.4 \mathrm{~Hz}, 1 \mathrm{H}), 7.43(\mathrm{t}, J=7.7 \mathrm{~Hz}$, 1H), $7.36(\mathrm{~d}, J=7.5 \mathrm{~Hz}, 1 \mathrm{H}), 7.28(2 \mathrm{H}), 6.89-6.83(2 \mathrm{H}), 6.78(\mathrm{~d}, J=9.1 \mathrm{~Hz}, 1 \mathrm{H})$, $5.97(\mathrm{~d}, J=14.0 \mathrm{~Hz}, 1 \mathrm{H}), 3.48(\mathrm{~s}, 3 \mathrm{H}), 3.43(\mathrm{q}, J=7.0 \mathrm{~Hz}, 4 \mathrm{H}), 2.89-2.86(\mathrm{t}, J=6.2$ $\mathrm{Hz}, 2 \mathrm{H}), 2.73-2.63(2 \mathrm{H}), 1.84(\mathrm{~s}, 3 \mathrm{H}), 1.76(\mathrm{~s}, 3 \mathrm{H}), 1.21(\mathrm{t}, J=7.0 \mathrm{~Hz}, 6 \mathrm{H}) .{ }^{13} \mathrm{C}$ NMR $\left(100 \mathrm{MHz}, \mathrm{CDCl}_{3}\right) \delta 172.73,168.02,167.73,156.11,151.34,149.19,148.06$, $142.78,140.88,137.95,135.43,133.17,131.76,131.07,129.45,129.41,128.66$, $127.58,125.18,122.44,122.25,113.65,111.82,110.56,100.60,97.23,49.20,45.00$, 29.69, 28.46, 28.11, 12.59. MS (ESI): $\mathrm{m} / \mathrm{z}=545.2[\mathrm{M}]^{+}$.

CC21: Yield: 29\%. ${ }^{1} \mathrm{H}$ NMR (400 MHz, MeOD) $\delta 8.49(\mathrm{~d}, J=14.1 \mathrm{~Hz}, 1 \mathrm{H}), 8.16(\mathrm{~d}$, $J=7.8 \mathrm{~Hz}, 1 \mathrm{H}), 7.76-7.70(1 \mathrm{H}), 7.65(\mathrm{~d}, J=8.6,1 \mathrm{H}), 7.50$ (d, $J=7.2 \mathrm{~Hz}, 1 \mathrm{H}), 7.44$ $-7.37(2 \mathrm{H}), 7.28(2 \mathrm{H}), 6.98(\mathrm{~d}, J=9.1,1 \mathrm{H}), 6.83(, 2 \mathrm{H}), 6.31(1 \mathrm{H}), 6.23(\mathrm{~d}, J=10.0$ $\mathrm{Hz}, 1 \mathrm{H}), 3.63-3.48(7 \mathrm{H}), 1.75(\mathrm{~s}, 6 \mathrm{H}), 1.28(\mathrm{t}, 6 \mathrm{H}) . \mathrm{MS}(\mathrm{ESI}): \mathrm{m} / \mathrm{z}=519.2[\mathrm{M}]^{+}$. $\operatorname{HRMS}(\mathrm{m} / \mathrm{z}):[\mathrm{M}]^{+}$calcd for $\left[\mathrm{C}_{34} \mathrm{H}_{35} \mathrm{~N}_{2} \mathrm{O}_{3}\right]^{+}$519.2642, found 519.2633.

CC22: Yield: $70 \% .{ }^{1} \mathrm{H}$ NMR (400 MHz, MeOD) $\delta 8.31(\mathrm{~s}, 1 \mathrm{H}), 8.26(\mathrm{~d}, J=8.1 \mathrm{~Hz}$, $1 \mathrm{H}), 8.03(\mathrm{~d}, J=7.9 \mathrm{~Hz}, 1 \mathrm{H}), 7.92(\mathrm{~s}, 1 \mathrm{H}), 7.78(\mathrm{t}, J=7.6 \mathrm{~Hz}, 1 \mathrm{H}), 7.72(\mathrm{t}, J=7.8 \mathrm{~Hz}$, 2H), $7.54(\mathrm{~d}, J=8.3 \mathrm{~Hz}, 1 \mathrm{H}), 7.39-7.34(2 \mathrm{H}), 7.21-7.14(\mathrm{~m}, 2 \mathrm{H}), 7.08(\mathrm{~d}, J=9.3$ $\mathrm{Hz}, 1 \mathrm{H}), 3.95(\mathrm{~s}, 3 \mathrm{H}), 3.65(\mathrm{q}, J=6.9 \mathrm{~Hz}, 4 \mathrm{H}), 3.07(\mathrm{t}, J=6.4 \mathrm{~Hz}, 2 \mathrm{H}), 2.88(\mathrm{t}, J=6.4$ $\mathrm{Hz}, 2 \mathrm{H}), 1.30$ (t, $J=6.9 \mathrm{~Hz}, 6 \mathrm{H}) . \mathrm{MS}(\mathrm{ESI}): \mathrm{m} / \mathrm{z}=503.2[\mathrm{M}]^{+} . \operatorname{HRMS}(\mathrm{m} / \mathrm{z}):[\mathrm{M}]^{+}$ calcd for $\left[\mathrm{C}_{33} \mathrm{H}_{31} \mathrm{~N}_{2} \mathrm{O}_{3}\right]^{+}$503.2329, found 503.2316.

CC23: Yield: $36 \% .{ }^{1} \mathrm{H}$ NMR (400 MHz, MeOD) $\delta 8.44(\mathrm{~d}, J=15.4 \mathrm{~Hz}, 1 \mathrm{H}), 8.12$ (d, 
$J=7.3 \mathrm{~Hz}, 1 \mathrm{H}), 8.07$ (d, $J=7.7 \mathrm{~Hz}, 1 \mathrm{H}), 7.98(\mathrm{~s}, 1 \mathrm{H}), 7.72-7.66(2 \mathrm{H}), 7.62(\mathrm{~s}, 1 \mathrm{H})$, $7.53(\mathrm{~d}, J=8.0 \mathrm{~Hz}, 1 \mathrm{H}), 7.42-7.36(\mathrm{~m}, 2 \mathrm{H}), 7.32$ (d, $J=7.4 \mathrm{~Hz}, 1 \mathrm{H}), 7.29$ (d, $J=$ $9.7 \mathrm{~Hz}, 1 \mathrm{H}), 7.19(\mathrm{~s}, 1 \mathrm{H}), 7.12$ (d, $J=15.7 \mathrm{~Hz}, 1 \mathrm{H}), 7.05(\mathrm{~s}, 1 \mathrm{H}), 3.90(\mathrm{~s}, 3 \mathrm{H}), 3.62(\mathrm{q}$, $J=6.8 \mathrm{~Hz}, 4 \mathrm{H}), 1.29(\mathrm{t}, J=6.8 \mathrm{~Hz}, 6 \mathrm{H}) . \operatorname{HRMS}(\mathrm{m} / \mathrm{z}):[\mathrm{M}]^{+}$calcd for $\left[\mathrm{C}_{31} \mathrm{H}_{29} \mathrm{~N}_{2} \mathrm{O}_{3}\right]^{+}$ 477.2173, found 477.2162.

CC24: Yield: 52\%. ${ }^{1} \mathrm{H}$ NMR (400 MHz, MeOD) $\delta 8.23$ (d, $\left.J=7.6 \mathrm{~Hz}, 1 \mathrm{H}\right), 8.11$ (s, 1H), $7.93(\mathrm{~d}, J=7.4 \mathrm{~Hz}, 1 \mathrm{H}), 7.82-7.66(3 \mathrm{H}), 7.36(\mathrm{~d}, J=7.5 \mathrm{~Hz}, 1 \mathrm{H}), 7.32$ (d, $J=$ $7.4 \mathrm{~Hz}, 1 \mathrm{H}), 7.26-7.12(3 \mathrm{H}), 7.04(\mathrm{~d}, J=9.5 \mathrm{~Hz}, 1 \mathrm{H}), 6.98(\mathrm{~s}, 1 \mathrm{H}), 3.62$ (q, $J=7.0$ $\mathrm{Hz}, 4 \mathrm{H}), 2.87$ (t, $J=4.4 \mathrm{~Hz}, 2 \mathrm{H}), 2.79$ (t, $J=4.4 \mathrm{~Hz}, 2 \mathrm{H}), 1.30$ (t, $J=7.0 \mathrm{~Hz}, 6 \mathrm{H})$. HRMS (m/z): $[\mathrm{M}]^{+}$calcd for $\left[\mathrm{C}_{32} \mathrm{H}_{29} \mathrm{~N}_{2} \mathrm{O}_{3}\right]^{+}$489.2173, found 489.2159 .

CC25: Yield: 40\%. ${ }^{1} \mathrm{H}$ NMR (400 MHz, MeOD) $\delta 8.51(\mathrm{~d}, J=15.5 \mathrm{~Hz}, 1 \mathrm{H}), 8.17$ (d, $J=7.2 \mathrm{~Hz}, 1 \mathrm{H}), 8.07(\mathrm{~d}, J=4.9 \mathrm{~Hz}, 1 \mathrm{H}), 8.02(\mathrm{~s}, 1 \mathrm{H}), 7.75-7.67(2 \mathrm{H}), 7.48(\mathrm{dd}, J=$ 7.6, 3.6 Hz, 1H), 7.42 (d, $J=7.4 \mathrm{~Hz}, 1 \mathrm{H}), 7.30$ (d, $J=4.4 \mathrm{~Hz}, 1 \mathrm{H}), 7.27$ (s, 1H), 7.26 (s, 1H), $7.21(\mathrm{~s}, 1 \mathrm{H}), 7.16$ (d, $J=15.6 \mathrm{~Hz}, 1 \mathrm{H}), 7.07$ (d, $J=9.2 \mathrm{~Hz}, 1 \mathrm{H}), 7.05$ (s, 1H), $3.62(\mathrm{q}, J=7.0 \mathrm{~Hz}, 4 \mathrm{H}), 1.28(\mathrm{t}, J=7.0 \mathrm{~Hz}, 6 \mathrm{H}) . \operatorname{HRMS}(\mathrm{m} / \mathrm{z}):[\mathrm{M}]^{+}$calcd for $\left[\mathrm{C}_{30} \mathrm{H}_{27} \mathrm{~N}_{2} \mathrm{O}_{3}\right]^{+}$463.2016, found 463.2011.

CC26: Yield: 57\%. ${ }^{1} \mathrm{H}$ NMR (400 MHz, MeOD) $\delta 8.23$ (d, $\left.J=7.7 \mathrm{~Hz}, 1 \mathrm{H}\right), 8.09$ (s, 1H), $7.81(\mathrm{~d}, J=7.8 \mathrm{~Hz}, 1 \mathrm{H}), 7.76(\mathrm{t}, J=7.4 \mathrm{~Hz}, 1 \mathrm{H}), 7.69$ (t, $J=7.6 \mathrm{~Hz}, 1 \mathrm{H}), 7.61$ $(\mathrm{d}, J=7.2 \mathrm{~Hz}, 2 \mathrm{H}), 7.56-7.50(3 \mathrm{H}), 7.47(\mathrm{~d}, J=7.9 \mathrm{~Hz}, 1 \mathrm{H}), 7.31(\mathrm{~d}, J=7.5 \mathrm{~Hz}$, 1H), $7.26(\mathrm{~d}, J=7.7 \mathrm{~Hz}, 1 \mathrm{H}), 7.21$ (d, $J=7.6 \mathrm{~Hz}, 1 \mathrm{H}), 7.17(\mathrm{~d}, J=9.6 \mathrm{~Hz}, 1 \mathrm{H}), 7.10$ $(\mathrm{d}, J=9.7 \mathrm{~Hz}, 1 \mathrm{H}), 7.01(\mathrm{~s}, 1 \mathrm{H}), 3.62(\mathrm{q}, J=7.1 \mathrm{~Hz}, 4 \mathrm{H}), 2.73(\mathrm{t}, J=7.2 \mathrm{~Hz}, 2 \mathrm{H})$, $2.60(\mathrm{t}, J=7.2 \mathrm{~Hz}, 2 \mathrm{H}), 1.27(\mathrm{t}, J=7.1 \mathrm{~Hz}, 6 \mathrm{H}) .{ }^{13} \mathrm{C} \mathrm{NMR}(100 \mathrm{MHz}, \mathrm{MeOD}) \delta$ $170.57,169.82,167.85,158.51,154.26,144.32,137.21,134.29,132.42,131.92$, $130.98,130.60,129.85,129.25,129.20,129.11,129.03,128.78,128.75,126.94$, $123.40,121.19,120.42,116.10,115.56,111.85,111.35,96.37,45.25,29.35,27.89$, 11.40. MS (ESI): $\mathrm{m} / \mathrm{z}=565.2[\mathrm{M}]^{+}$.

CC27: Yield: 42\%. ${ }^{1} \mathrm{H}$ NMR (400 MHz, MeOD) $\delta 8.28$ (d, $\left.J=15.4 \mathrm{~Hz}, 1 \mathrm{H}\right), 8.08-$ $7.98(2 \mathrm{H}), 7.66(\mathrm{~s}, 2 \mathrm{H}), 7.61(5 \mathrm{H}), 7.45(\mathrm{~d}, J=7.0 \mathrm{~Hz}, 1 \mathrm{H}), 7.33(\mathrm{~d}, J=9.1 \mathrm{~Hz}, 2 \mathrm{H})$, $7.28(\mathrm{~d}, J=5.2 \mathrm{~Hz}, 2 \mathrm{H}), 7.07(3 \mathrm{H}), 6.69(\mathrm{~s}, 1 \mathrm{H}), 3.58(\mathrm{q}, J=6.9 \mathrm{~Hz}, 4 \mathrm{H}), 1.26(\mathrm{t}, J=$ $6.9 \mathrm{~Hz}, 6 \mathrm{H}) . \mathrm{MS}(\mathrm{ESI}): \mathrm{m} / \mathrm{z}=539.2[\mathrm{M}]^{+}$. HRMS (m/z): $[\mathrm{M}]^{+}$calcd for $\left[\mathrm{C}_{36} \mathrm{H}_{31} \mathrm{~N}_{2} \mathrm{O}_{3}\right]^{+}$ 
539.2329, found 539.2314

CC28: Yield: 52\%. ${ }^{1} \mathrm{H}$ NMR (400 MHz, MeOD) $\delta 8.27$ (d, $\left.J=7.7 \mathrm{~Hz}, 1 \mathrm{H}\right), 8.10$ (s, 1H), 7.89 (d, $J=7.9 \mathrm{~Hz}, 1 \mathrm{H}), 7.81(\mathrm{t}, J=7.3 \mathrm{~Hz}, 1 \mathrm{H}), 7.72(\mathrm{t}, J=7.4 \mathrm{~Hz}, 1 \mathrm{H}), 7.35$ (t, $J=7.7 \mathrm{~Hz}, 2 \mathrm{H}), 7.19(\mathrm{~d}, J=7.2 \mathrm{~Hz}, 1 \mathrm{H}), 7.16(\mathrm{~s}, 1 \mathrm{H}), 7.15-7.07$ (m, 2H), $7.04(\mathrm{~d}, J$ $=9.0 \mathrm{~Hz}, 1 \mathrm{H}), 3.63(\mathrm{q}, J=6.9 \mathrm{~Hz}, 4 \mathrm{H}), 3.24(\mathrm{t}, J=9.8 \mathrm{~Hz}, 2 \mathrm{H}), 2.74(\mathrm{t}, J=9.8 \mathrm{~Hz}$, 2H), $2.69(\mathrm{~s}, 3 \mathrm{H}), 1.28(\mathrm{t}, J=6.9 \mathrm{~Hz}, 6 \mathrm{H}) .{ }^{13} \mathrm{C} \mathrm{NMR}(100 \mathrm{MHz}, \mathrm{MeOD}) \delta 171.08$, $167.54,158.08$, 153.66, 147.43, 138.76, 137.10, 134.58, 132.66, 131.73, 131.09, $129.77,129.02,128.94,128.49,125.71,124.86,123.00,121.46,120.79,115.35$, $114.64,113.29,112.88,111.55,96.69,45.07,31.68,29.35,22.34,13.04,11.44 . \mathrm{MS}$ (ESI): $\mathrm{m} / \mathrm{z}=503.2[\mathrm{M}]^{+}$.

CC29: Yield: 36\%. ${ }^{1} \mathrm{H}$ NMR (400 MHz, MeOD) $\delta 8.06(\mathrm{~d}, J=14.8 \mathrm{~Hz}, 1 \mathrm{H}), 7.98$ (s, $1 \mathrm{H}), 7.82(\mathrm{~d}, J=7.2 \mathrm{~Hz}, 1 \mathrm{H}), 7.54(\mathrm{~s}, 2 \mathrm{H}), 7.33(\mathrm{~d}, J=9.1 \mathrm{~Hz}, 1 \mathrm{H}), 7.26-7.16(3 \mathrm{H})$, $7.13(\mathrm{~d}, J=6.8 \mathrm{~Hz}, 1 \mathrm{H}), 6.92(\mathrm{~s}, 1 \mathrm{H}), 6.87(\mathrm{~d}, J=9.4 \mathrm{~Hz}, 1 \mathrm{H}), 6.74(\mathrm{~d}, J=14.6 \mathrm{~Hz}$, 1H), $6.67(\mathrm{~s}, 1 \mathrm{H}), 3.55$ (q, $J=6.3 \mathrm{~Hz}, 4 \mathrm{H}), 2.66(\mathrm{~s}, 3 \mathrm{H}), 1.28$ (t, $J=6.1 \mathrm{~Hz}, 6 \mathrm{H})$. MS (ESI): $\mathrm{m} / \mathrm{z}=477.2[\mathrm{M}]^{+}$. HRMS $(\mathrm{m} / \mathrm{z}):[\mathrm{M}]^{+}$calcd for $\left[\mathrm{C}_{31} \mathrm{H}_{29} \mathrm{~N}_{2} \mathrm{O}_{3}\right]^{+}$477.2173, found 477.2163 .

CC30: Yield: 28\%. ${ }^{1} \mathrm{H}$ NMR (400 MHz, MeOD) $\delta 8.78$ (s, 1H, NH), 8.27 (d, $J=7.5$ $\mathrm{Hz}, 1 \mathrm{H}), 8.12$ (s, 1H), 8.06 (d, $J=7.2 \mathrm{~Hz}, 1 \mathrm{H}), 7.78$ (t, $J=7.6 \mathrm{~Hz}, 1 \mathrm{H}), 7.72$ (d, $J=$ $7.6 \mathrm{~Hz}, 1 \mathrm{H}), 7.70(\mathrm{~d}, J=7.2 \mathrm{~Hz}, 1 \mathrm{H}), 7.62(\mathrm{dd}, J=7.6 \mathrm{~Hz}, 1 \mathrm{H}), 7.52$ (dd, $J=7.6 \mathrm{~Hz}$, 1H), 7.35 (d, $J=4.8 \mathrm{~Hz}, 1 \mathrm{H}), 7.33$ (s, 1H), 7.29 (d, $J=7.4 \mathrm{~Hz}, 1 \mathrm{H}), 7.06$ (d, $J=9.0$ $\mathrm{Hz}, 1 \mathrm{H}), 6.97(\mathrm{~d}, J=9.1 \mathrm{~Hz}, 1 \mathrm{H}), 2.93$ (t, $J=3.6 \mathrm{~Hz}, 2 \mathrm{H}), 2.47$ (t, $J=3.6 \mathrm{~Hz}, 2 \mathrm{H})$, $2.32(\mathrm{t}, J=3.6 \mathrm{~Hz}, 2 \mathrm{H}) . \mathrm{MS}(\mathrm{ESI}): \mathrm{m} / \mathrm{z}=448.0[\mathrm{M}]^{+}$. HRMS (m/z): $[\mathrm{M}]^{+}$calcd for $\left[\mathrm{C}_{29} \mathrm{H}_{22} \mathrm{NO}_{4}\right]^{+}$448.1543, found 448.1535 .

CC31: Yield: 27\%. ${ }^{1} \mathrm{H}$ NMR (400 MHz, MeOD) $\delta 8.03$ (dd, $J=6.2,3.6 \mathrm{~Hz}, 1 \mathrm{H}$ ), 7.93 (d, $J=7.6 \mathrm{~Hz}, 1 \mathrm{H}), 7.87(\mathrm{~s}, 1 \mathrm{H}), 7.67(\mathrm{~s}, 1 \mathrm{H}), 7.58$ (d, $J=3.6 \mathrm{~Hz}, 1 \mathrm{H}), 7.56$ (d, $J=$ $3.6 \mathrm{~Hz}, 1 \mathrm{H}), 7.44(\mathrm{~d}, J=7.9 \mathrm{~Hz}, 1 \mathrm{H}), 7.33(\mathrm{t}, J=7.6 \mathrm{~Hz}, 1 \mathrm{H}), 7.28(\mathrm{t}, J=7.6 \mathrm{~Hz}, 1 \mathrm{H})$, $7.20(\mathrm{dd}, J=7.6,3.6 \mathrm{~Hz}, 1 \mathrm{H}), 7.15(\mathrm{~d}, J=9.3 \mathrm{~Hz}, 1 \mathrm{H}), 6.76(\mathrm{~d}, J=1.8 \mathrm{~Hz}, 1 \mathrm{H}), 6.68$ $(\mathrm{dd}, J=7.4,1.6 \mathrm{~Hz}, 1 \mathrm{H}), 3.87(\mathrm{~s}, 3 \mathrm{H}), 2.98-2.93(\mathrm{~m}, 2 \mathrm{H}), 2.82-2.66(\mathrm{~m}, 2 \mathrm{H})$. $\operatorname{HRMS}(\mathrm{m} / \mathrm{z})$ : $[\mathrm{M}]^{+}$calcd for $\left[\mathrm{C}_{29} \mathrm{H}_{22} \mathrm{NO}_{4}\right]^{+} 448.1543$, found 448.1534 .

CC32: Yield: 21\%. ${ }^{1} \mathrm{H}$ NMR (400 MHz, DMSO) $\delta 7.97$ (d, $\left.J=7.7 \mathrm{~Hz}, 1 \mathrm{H}\right), 7.84$ (d, $J$ 
$=7.6 \mathrm{~Hz}, 1 \mathrm{H}), 7.80(\mathrm{t}, J=10.0 \mathrm{~Hz}, 1 \mathrm{H}), 7.75-7.65(\mathrm{~m}, 2 \mathrm{H}), 7.51(\mathrm{~s}, 1 \mathrm{H}), 7.45(\mathrm{~d}, J$ $=8.0 \mathrm{~Hz}, 1 \mathrm{H}), 7.32(\mathrm{~d}, J=7.6 \mathrm{~Hz}, 1 \mathrm{H}), 7.18(\mathrm{t}, J=7.2 \mathrm{~Hz}, 1 \mathrm{H}), 7.14-7.10(1 \mathrm{H})$, $6.89(\mathrm{~s}, 1 \mathrm{H}), 6.63(\mathrm{~d}, J=8.8 \mathrm{~Hz}, 1 \mathrm{H}), 6.58(\mathrm{~d}, J=8.8 \mathrm{~Hz}, 1 \mathrm{H}), 2.92-2.76(2 \mathrm{H}), 2.44$ $-2.30(2 \mathrm{H}) . \mathrm{MS}(\mathrm{ESI}): \mathrm{m} / \mathrm{z}=434.0[\mathrm{M}]^{+}$. $\operatorname{HRMS}(\mathrm{m} / \mathrm{z}):[\mathrm{M}]^{+}$calcd for $\left[\mathrm{C}_{28} \mathrm{H}_{20} \mathrm{NO}_{4}\right]^{+}$ 434.1387, found 434.1379.

CC33: Yield: 25\%. ${ }^{1} \mathrm{H}$ NMR (400 MHz, $\left.\mathrm{MeOD} / \mathrm{CDCl}_{3}\right) \delta 8.24(\mathrm{~d}, J=14.3 \mathrm{~Hz}, 1 \mathrm{H})$, $8.08(\mathrm{~d}, J=7.5 \mathrm{~Hz}, 1 \mathrm{H}), 7.59$ (t, $J=7.3 \mathrm{~Hz}, 1 \mathrm{H}), 7.54$ (d, $J=7.4 \mathrm{~Hz}, 1 \mathrm{H}), 7.49$ (d, $J=$ $7.6 \mathrm{~Hz}, 1 \mathrm{H}), 7.42$ (t, $J=7.6 \mathrm{~Hz}, 1 \mathrm{H}), 7.38$ (t, $J=8.8 \mathrm{~Hz}, 1 \mathrm{H}), 7.30$ (t, $J=7.6 \mathrm{~Hz}, 1 \mathrm{H})$, $7.21(\mathrm{~d}, J=7.3 \mathrm{~Hz}, 1 \mathrm{H}), 6.96(\mathrm{~s}, 1 \mathrm{H}), 6.86(\mathrm{~d}, J=8.7 \mathrm{~Hz}, 1 \mathrm{H}), 6.69(\mathrm{~d}, J=8.3 \mathrm{~Hz}$, $1 \mathrm{H}), 6.03(\mathrm{~d}, J=14.3 \mathrm{~Hz}, 1 \mathrm{H}), 3.67(\mathrm{~s}, 3 \mathrm{H}), 2.83(\mathrm{t}, J=5.6 \mathrm{~Hz}, 2 \mathrm{H}), 2.70(\mathrm{t}, J=5.6 \mathrm{~Hz}$, 2H), $1.72(\mathrm{~s}, 6 \mathrm{H}) .{ }^{13} \mathrm{C} \mathrm{NMR}\left(100 \mathrm{MHz}, \mathrm{MeOD} / \mathrm{CDCl}_{3}\right) \delta 175.42,167.80,161.59$, $154.75,147.26,142.49,141.30,140.27,134.11,133.12,131.20,130.59,129.00$, $128.87,128.76,127.49,126.15,122.13,120.97,116.69,114.83,111.48,102.84$, 101.78, 49.81, 31.12, 27.22, 27.12, 24.23. MS (ESI): $\mathrm{m} / \mathrm{z}=490.0[\mathrm{M}]^{+}$. HRMS (m/z): $[\mathrm{M}]^{+}$calcd for $\left[\mathrm{C}_{32} \mathrm{H}_{28} \mathrm{NO}_{4}\right]^{+} 490.2013$, found 490.2025.

CC34: Yield: 23\%. ${ }^{1} \mathrm{H}$ NMR (400 MHz, MeOD) $\delta 8.55$ (t, $\left.J=13.2 \mathrm{~Hz}, 1 \mathrm{H}\right), 7.89$ (dd, $J=6.8,3.6 \mathrm{~Hz}, 1 \mathrm{H}), 7.57-7.53(3 \mathrm{H}), 7.47(\mathrm{t}, J=7.5 \mathrm{~Hz}, 1 \mathrm{H}), 7.40(\mathrm{~d}, J=7.9 \mathrm{~Hz}$, 1H), $7.36-7.32(2 \mathrm{H}), 7.20(\mathrm{~d}, J=8.8 \mathrm{~Hz}, 1 \mathrm{H}), 6.98-6.89(\mathrm{~m}, 2 \mathrm{H}), 6.78(\mathrm{dd}, J=8.8$, $2.0 \mathrm{~Hz}, 1 \mathrm{H}), 6.48(\mathrm{~d}, J=13.1 \mathrm{~Hz}, 1 \mathrm{H}), 6.27$ (d, $J=12.6 \mathrm{~Hz}, 1 \mathrm{H}), 3.71(\mathrm{~s}, 3 \mathrm{H}), 1.76(\mathrm{~s}$, 6H). MS (ESI): $\mathrm{m} / \mathrm{z}=464.3[\mathrm{M}]+\operatorname{HRMS}(\mathrm{m} / \mathrm{z}):[\mathrm{M}]^{+}$calcd for $\left[\mathrm{C}_{30} \mathrm{H}_{26} \mathrm{NO}_{4}\right]^{+}$ 464.1856, found 464.1849. 


\section{Supplemental Spectra}

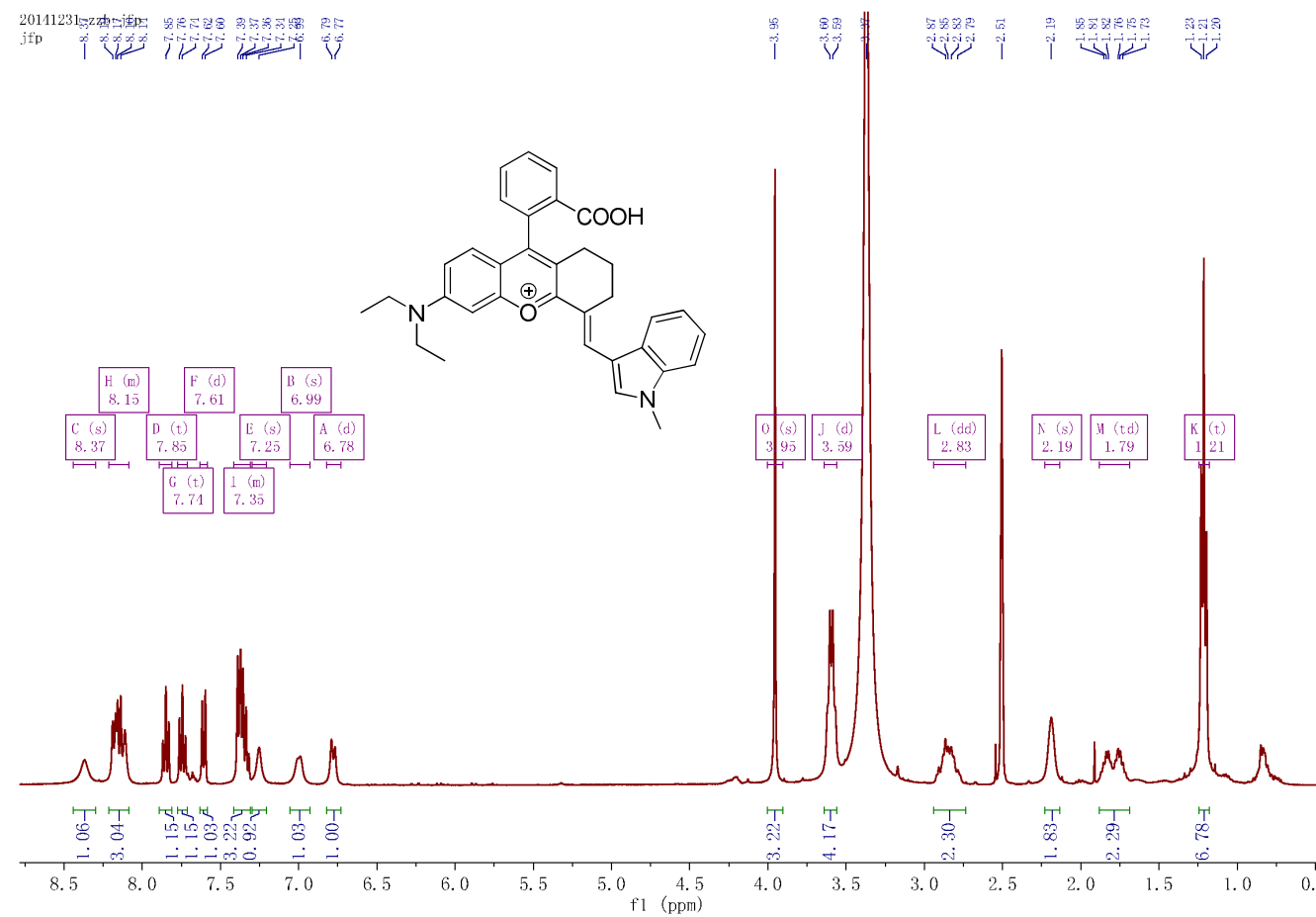

${ }^{1} \mathrm{H}$ NMR of CC 1 in $d_{6}$-DMSO.
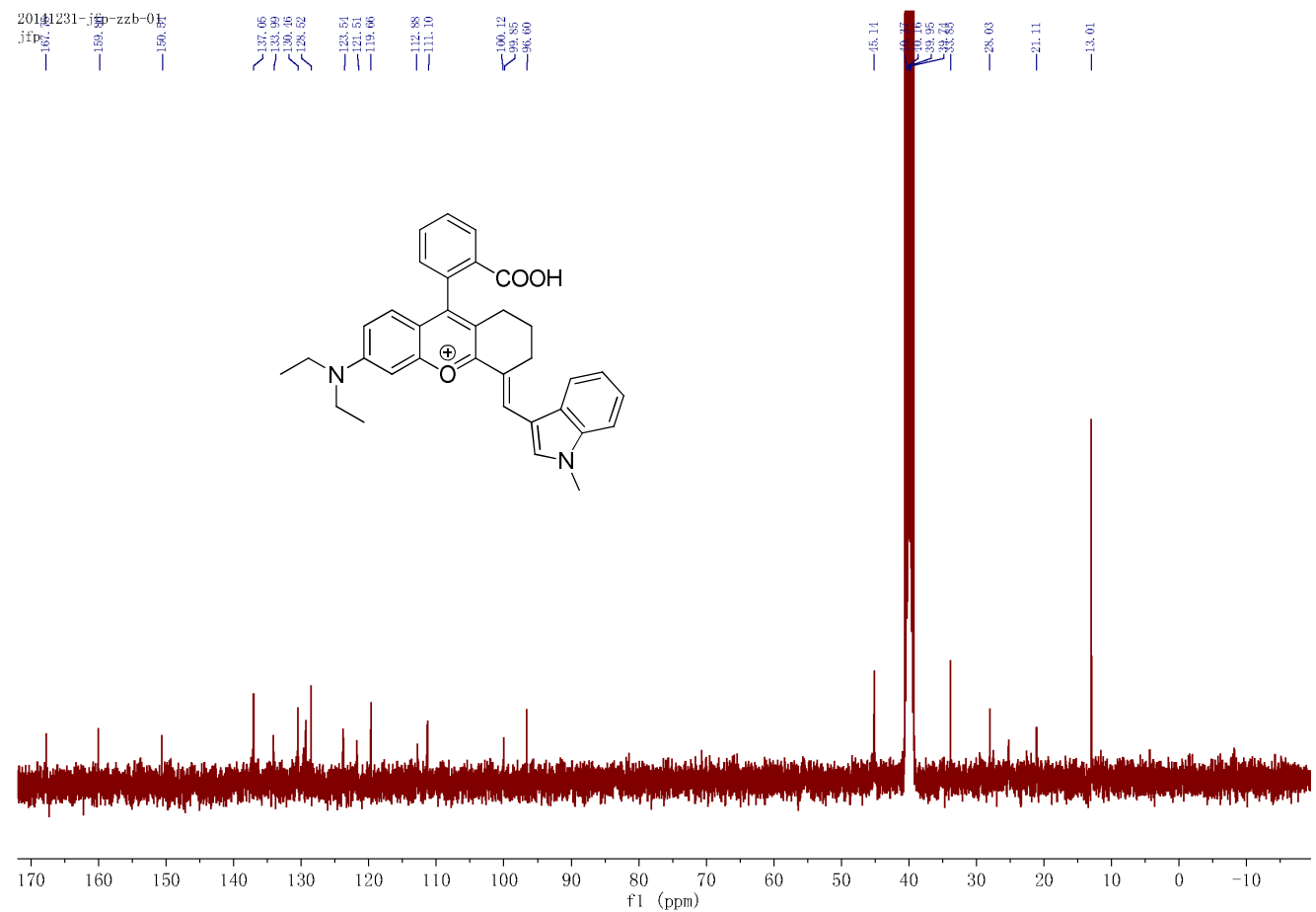

${ }^{1} \mathrm{C}$ NMR of CC $\mathbf{1}$ in $d_{6}$-DMSO. 


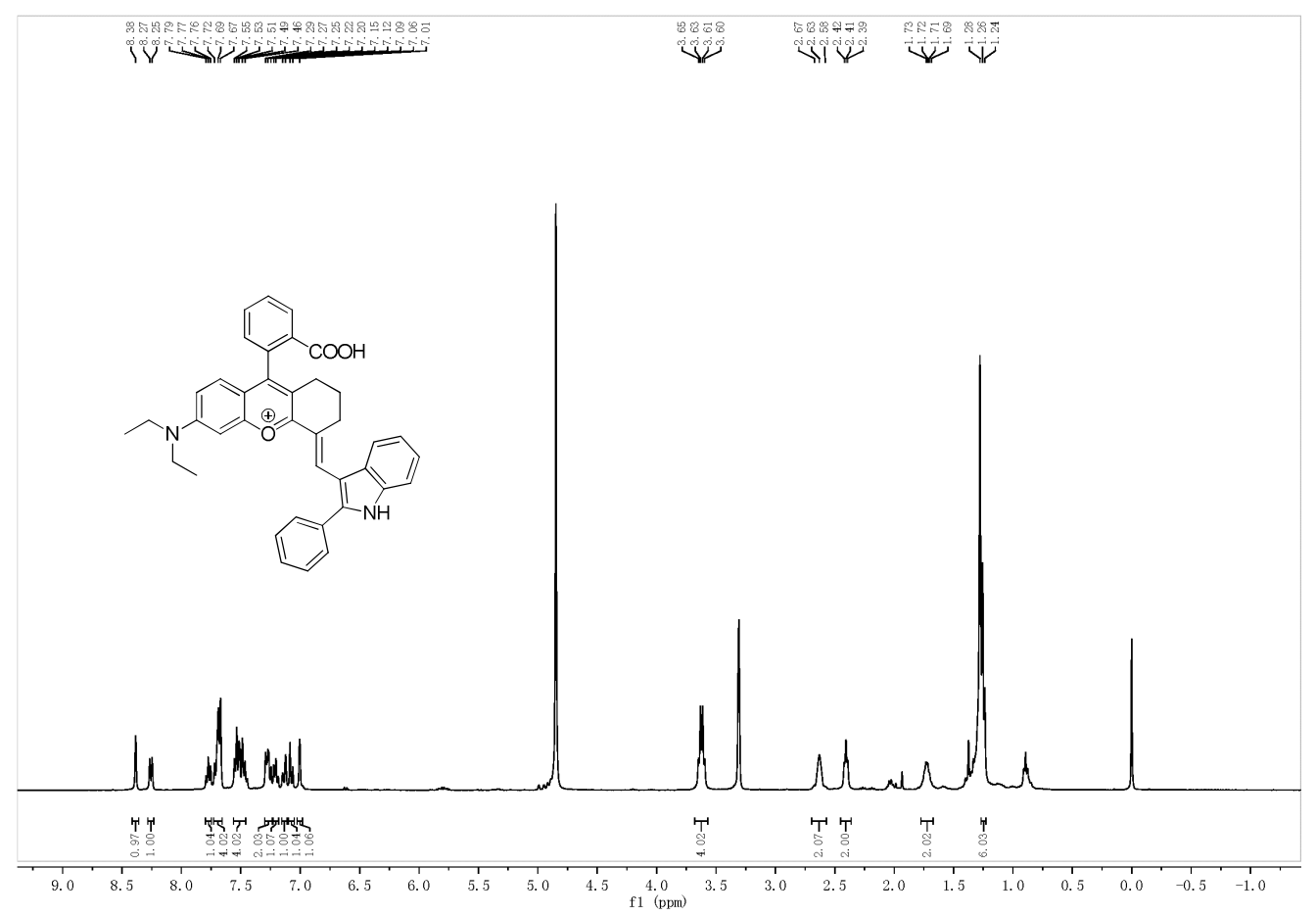

${ }^{1} \mathrm{H}$ NMR of CC 4 in MeOD.

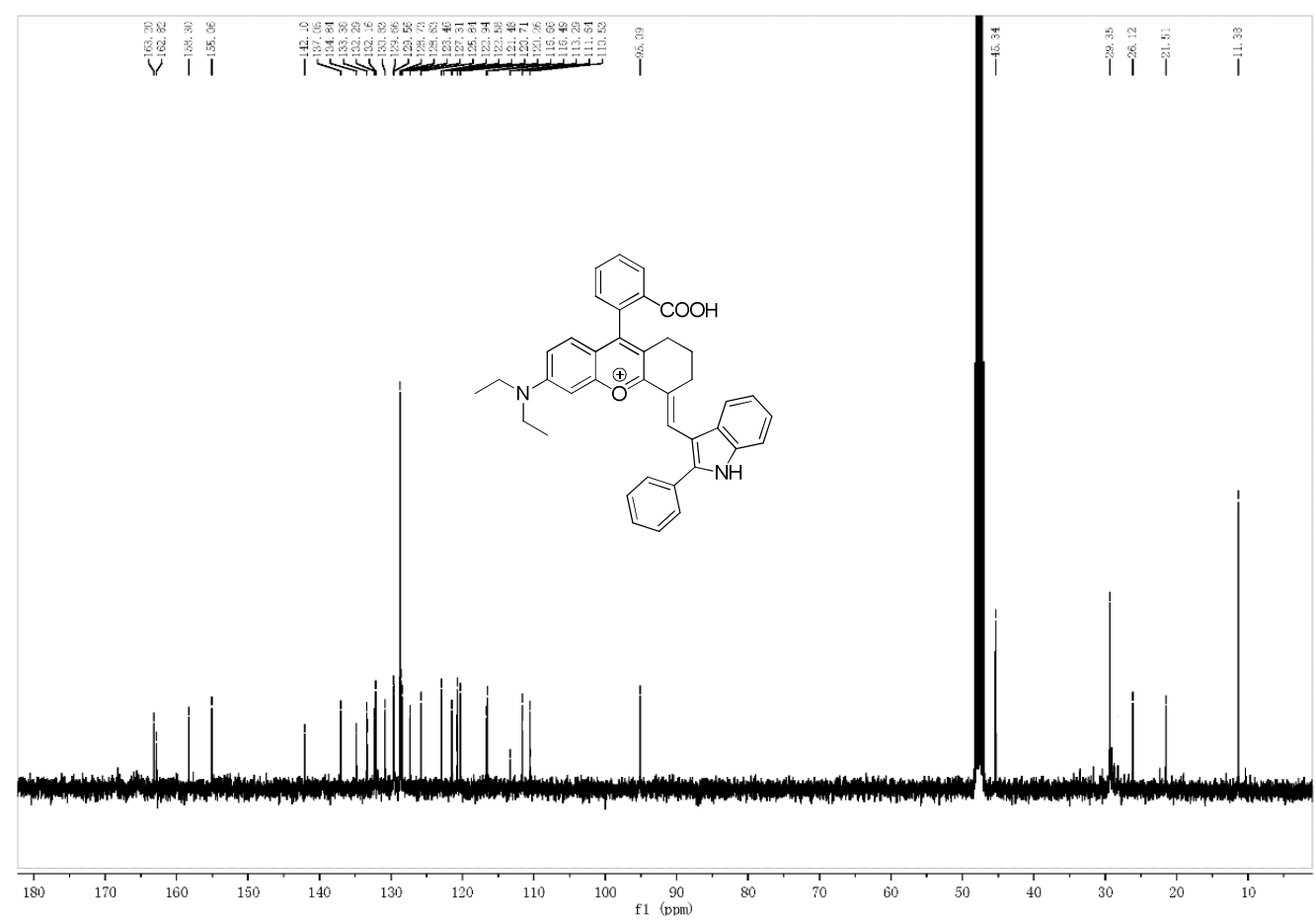

${ }^{13} \mathrm{C}$ NMR of CC 4 in MeOD. 


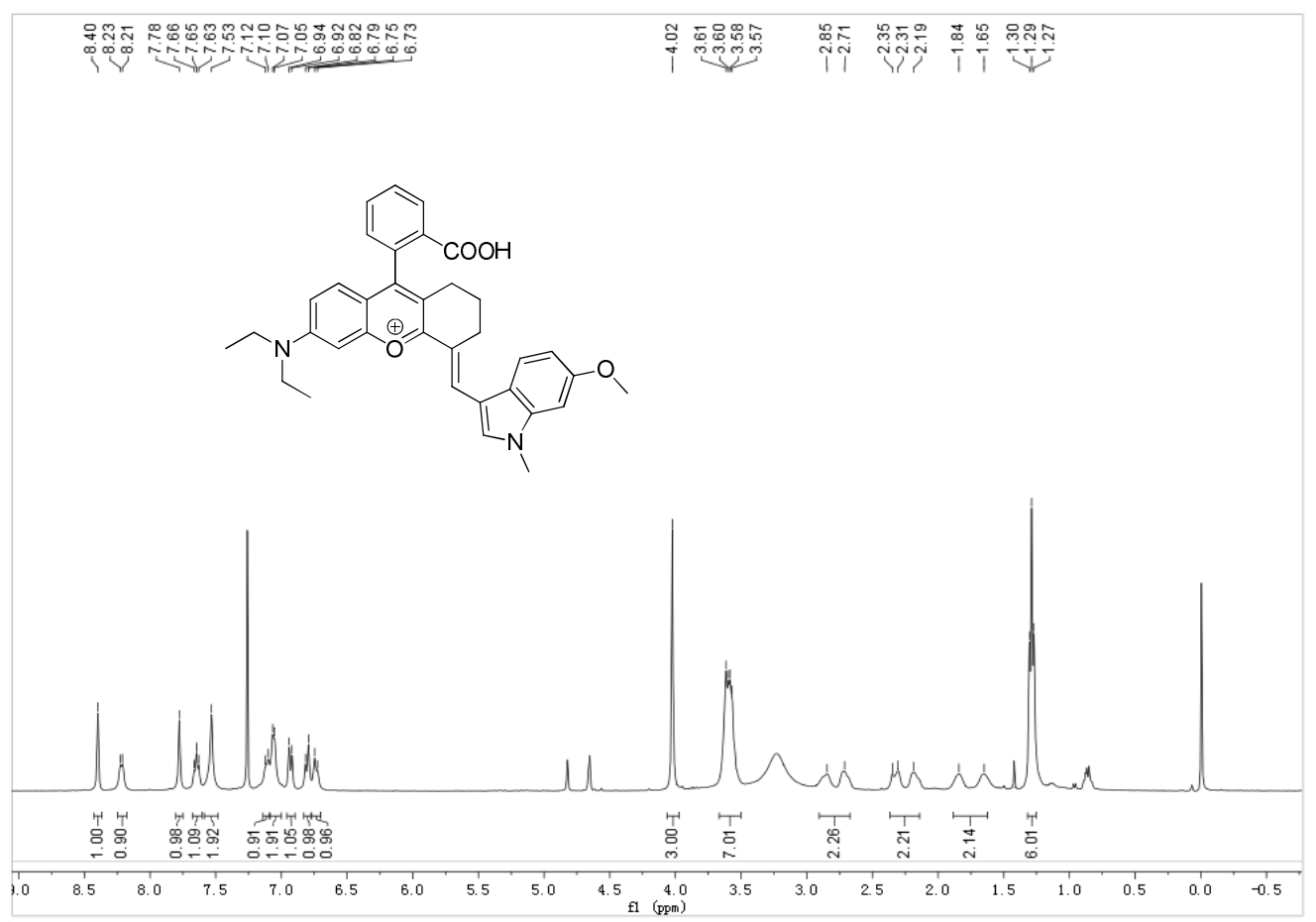

${ }^{1} \mathrm{H}$ NMR of CC 5 in $\mathrm{CDCl}_{3}$.

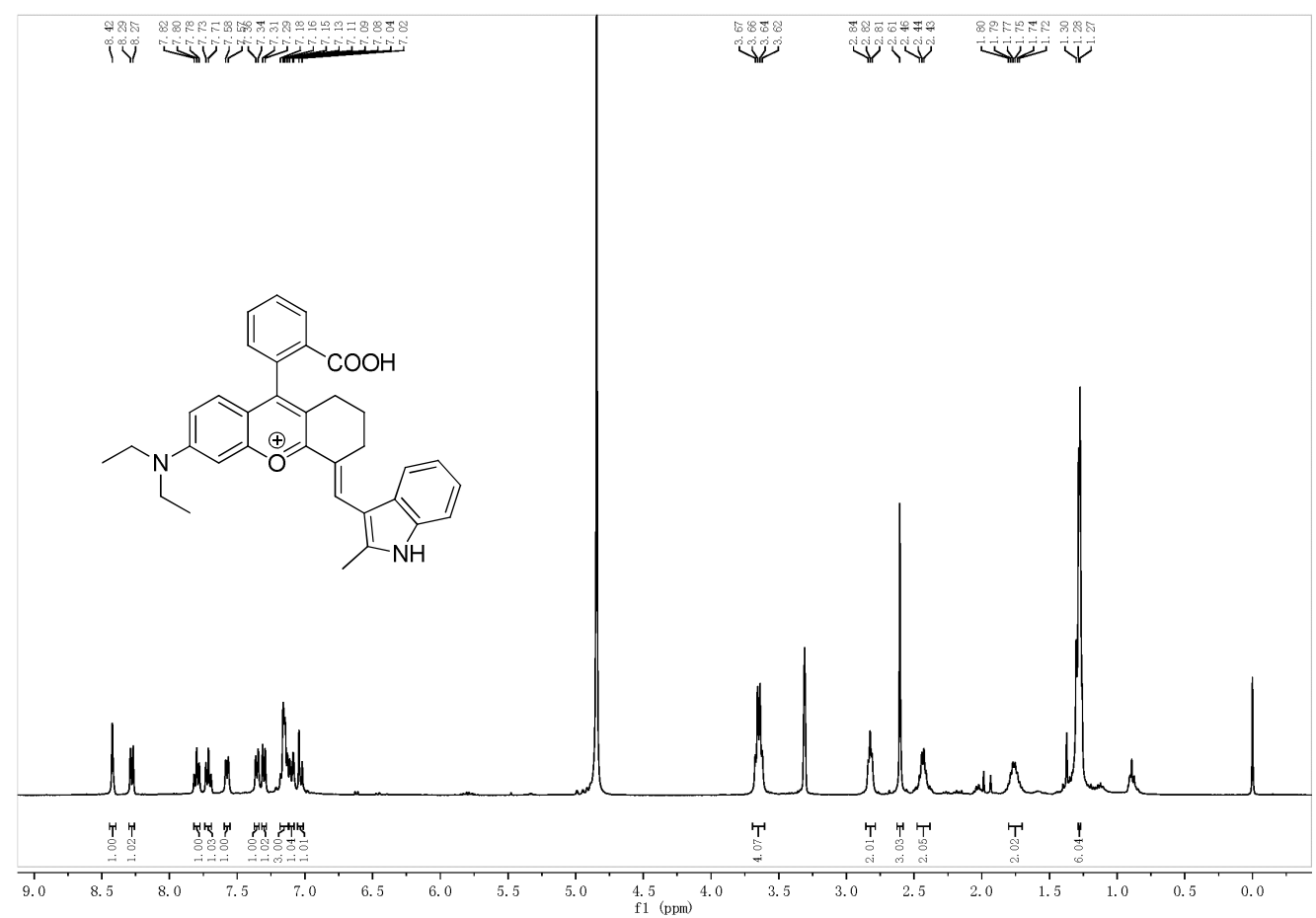

${ }^{1} \mathrm{H}$ NMR of CC 6 in MeOD 


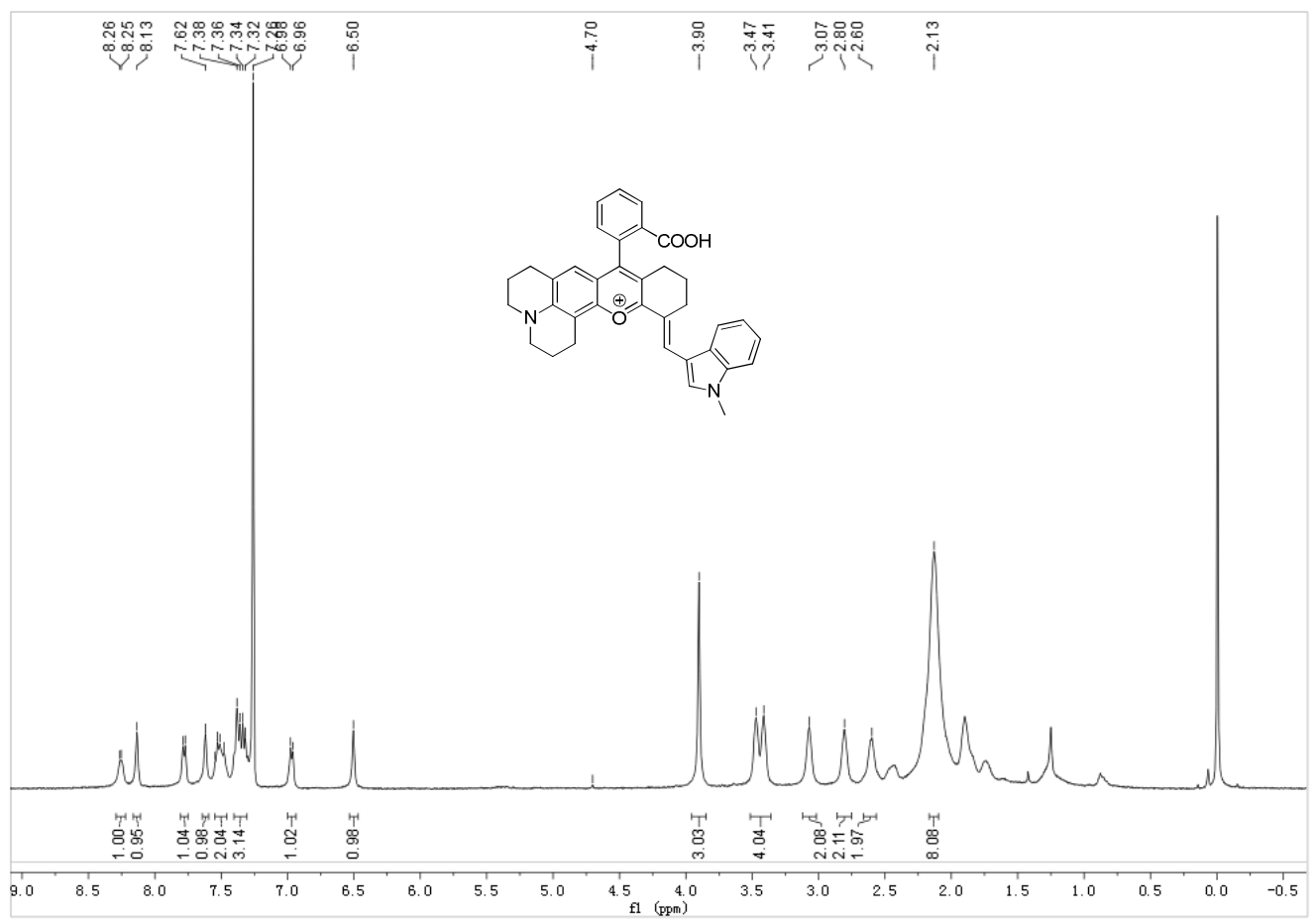

${ }^{1} \mathrm{H} \mathrm{NMR}$ of $\mathbf{C C} 15$ in $\mathrm{CDCl}_{3}$.

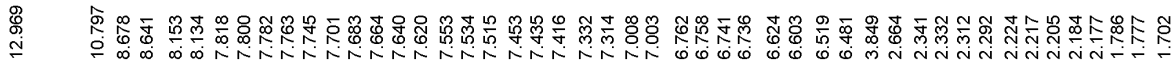
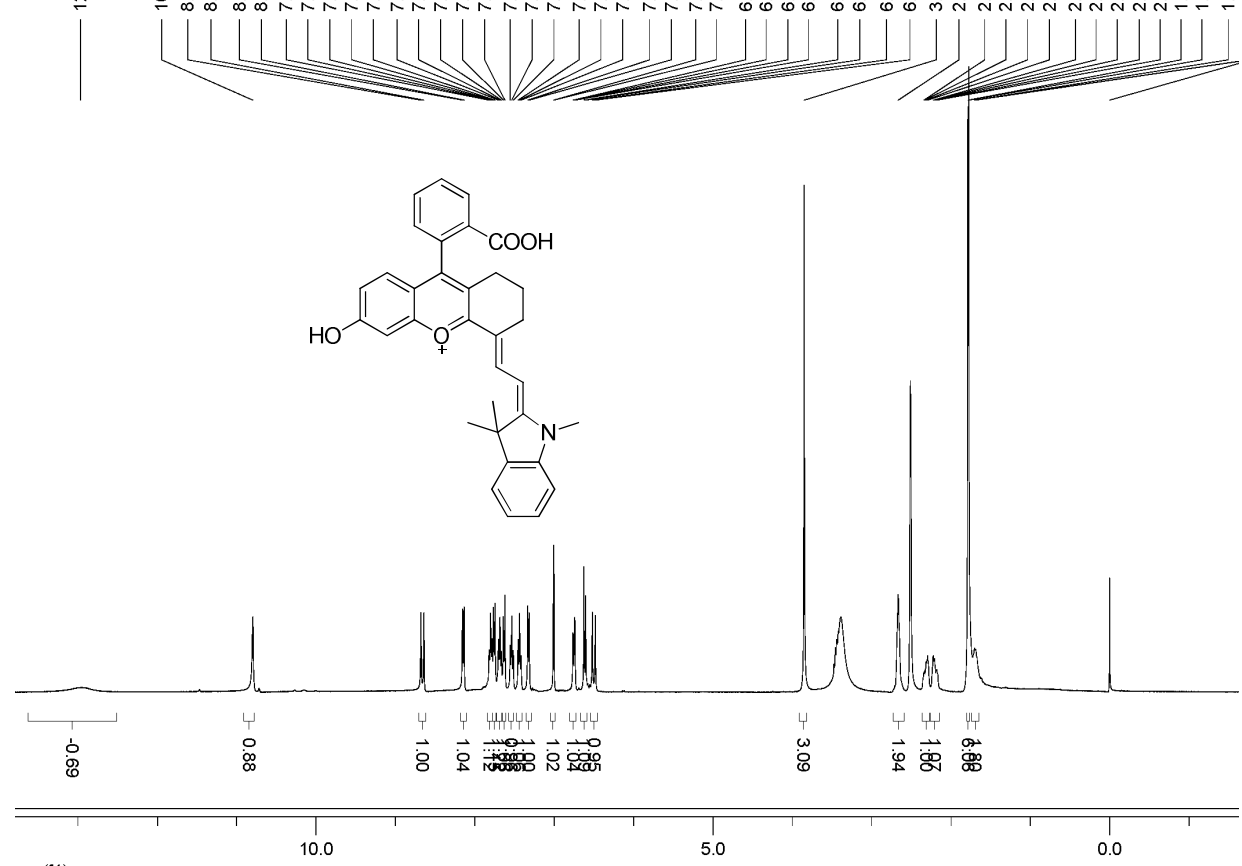

${ }^{1} \mathrm{H}$ NMR of $\mathbf{C C 1 7}$ in $d_{6}$-DMSO. 


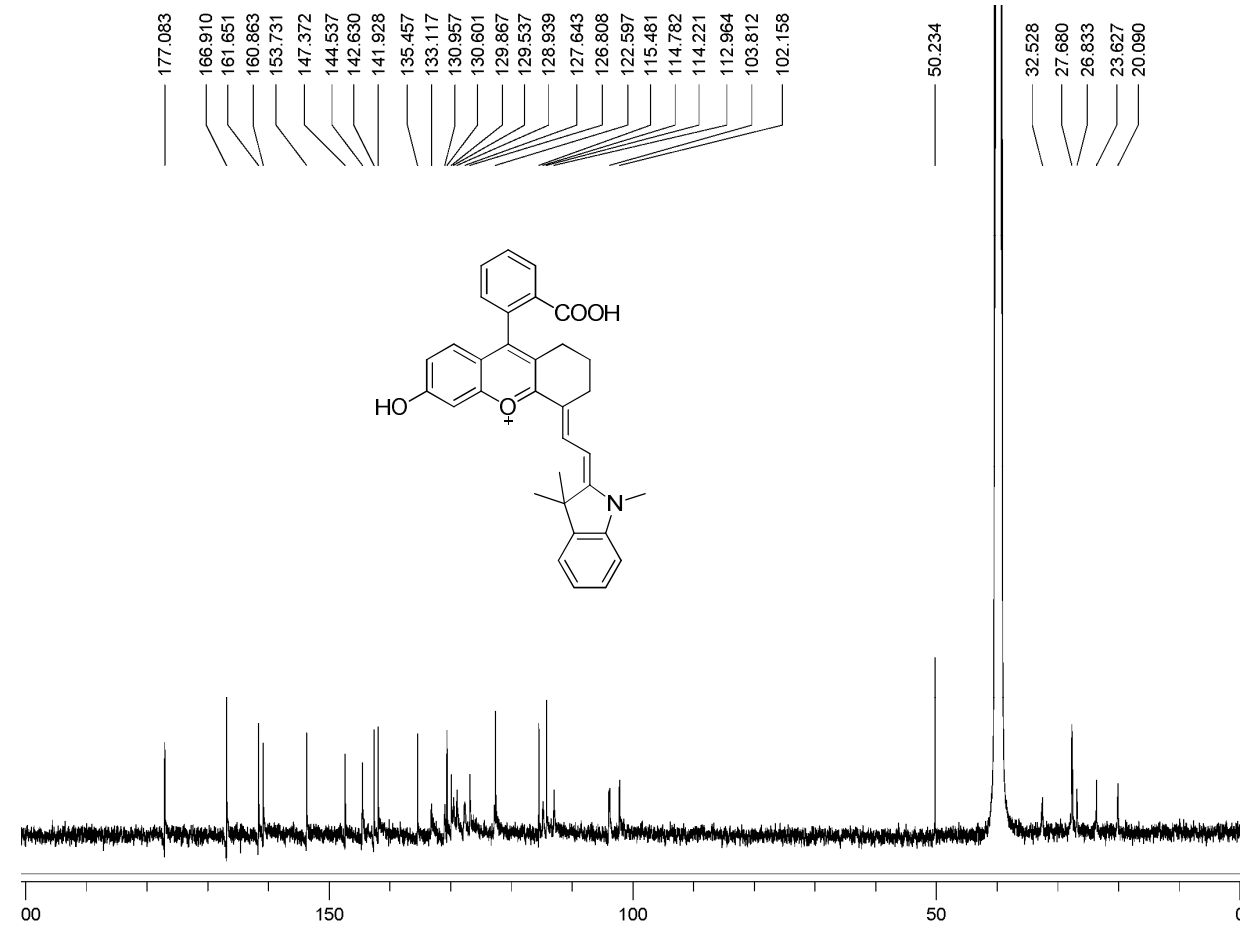

${ }^{1} \mathrm{C}$ NMR of CC17 in $d_{6}$-DMSO.

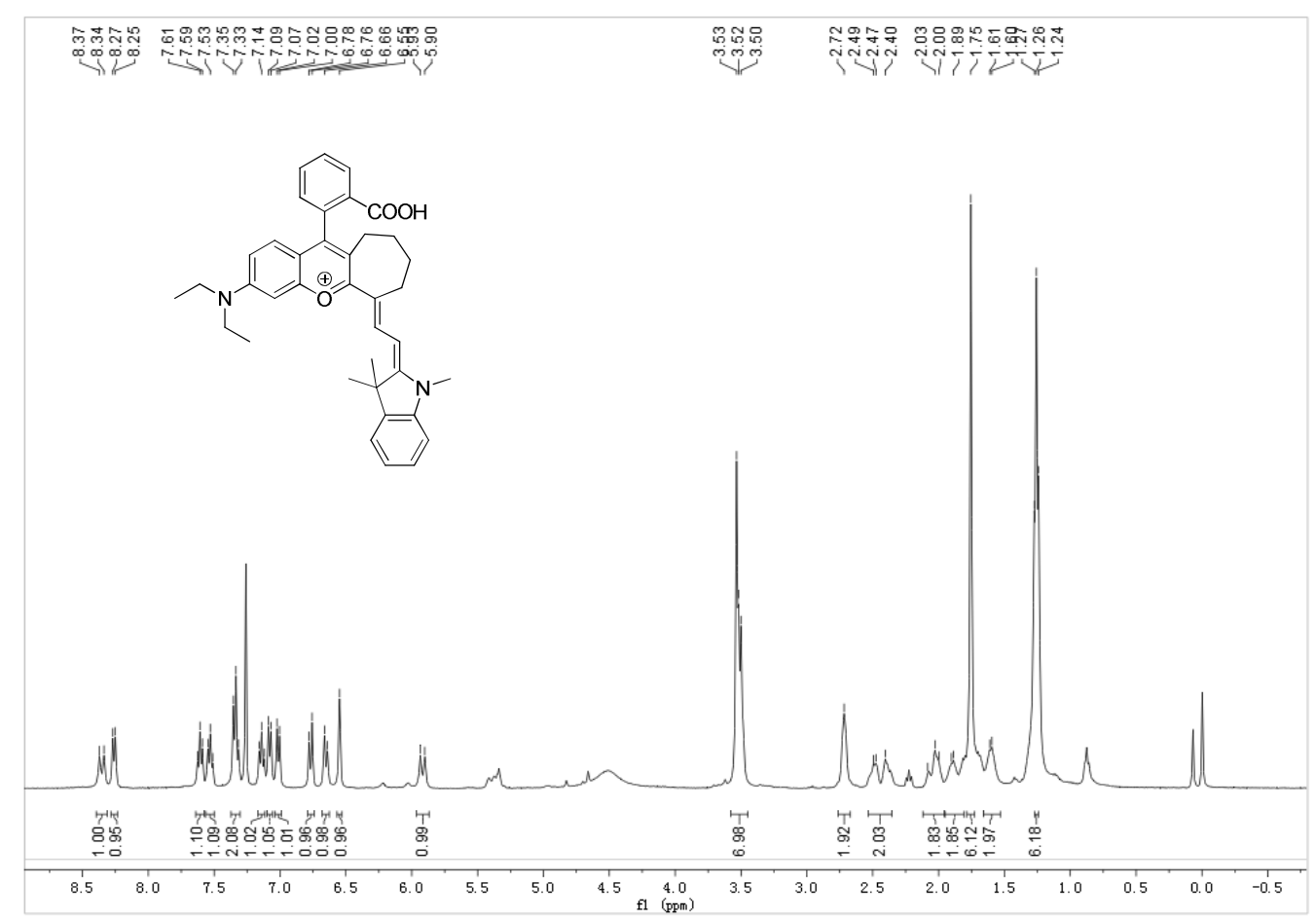

${ }^{1} \mathrm{H}$ NMR of $\mathbf{C C 1 9}$ in $\mathrm{CDCl}_{3}$. 


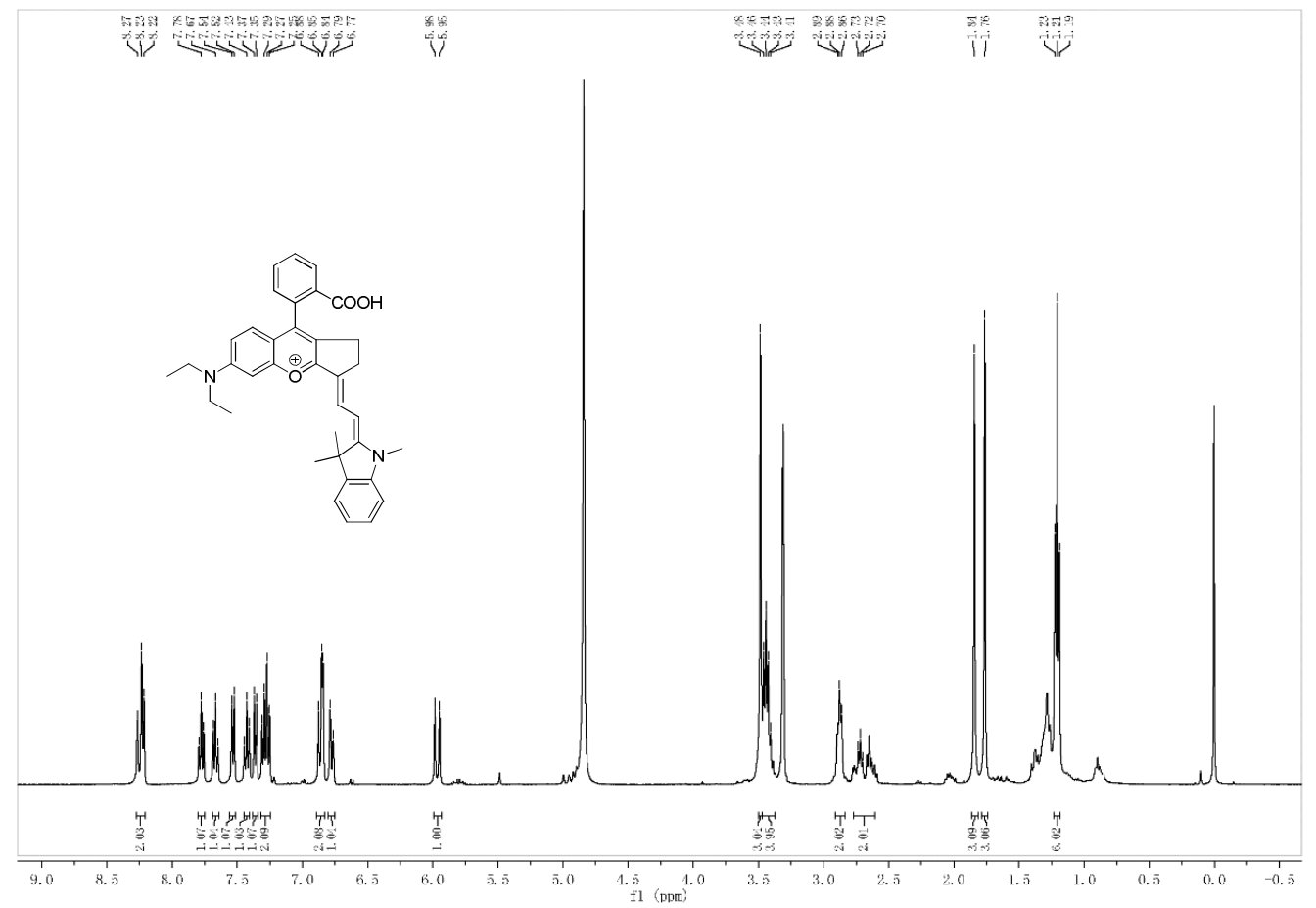

${ }^{1} \mathrm{H}$ NMR of CC20 in MeOD.

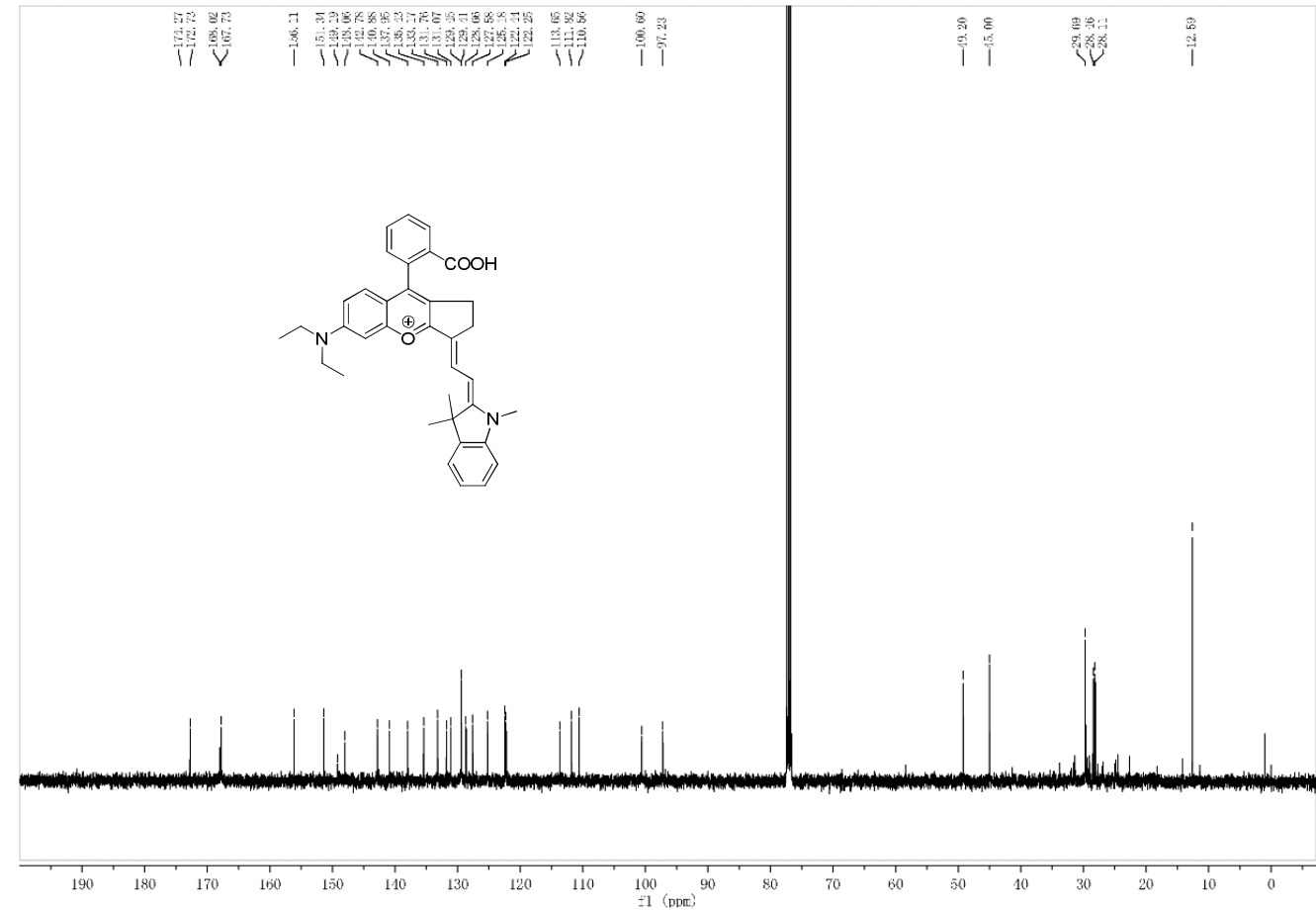

${ }^{13} \mathrm{C}$ NMR of $\mathbf{C C 2 0}$ in $\mathrm{CDCl}_{3}$. 


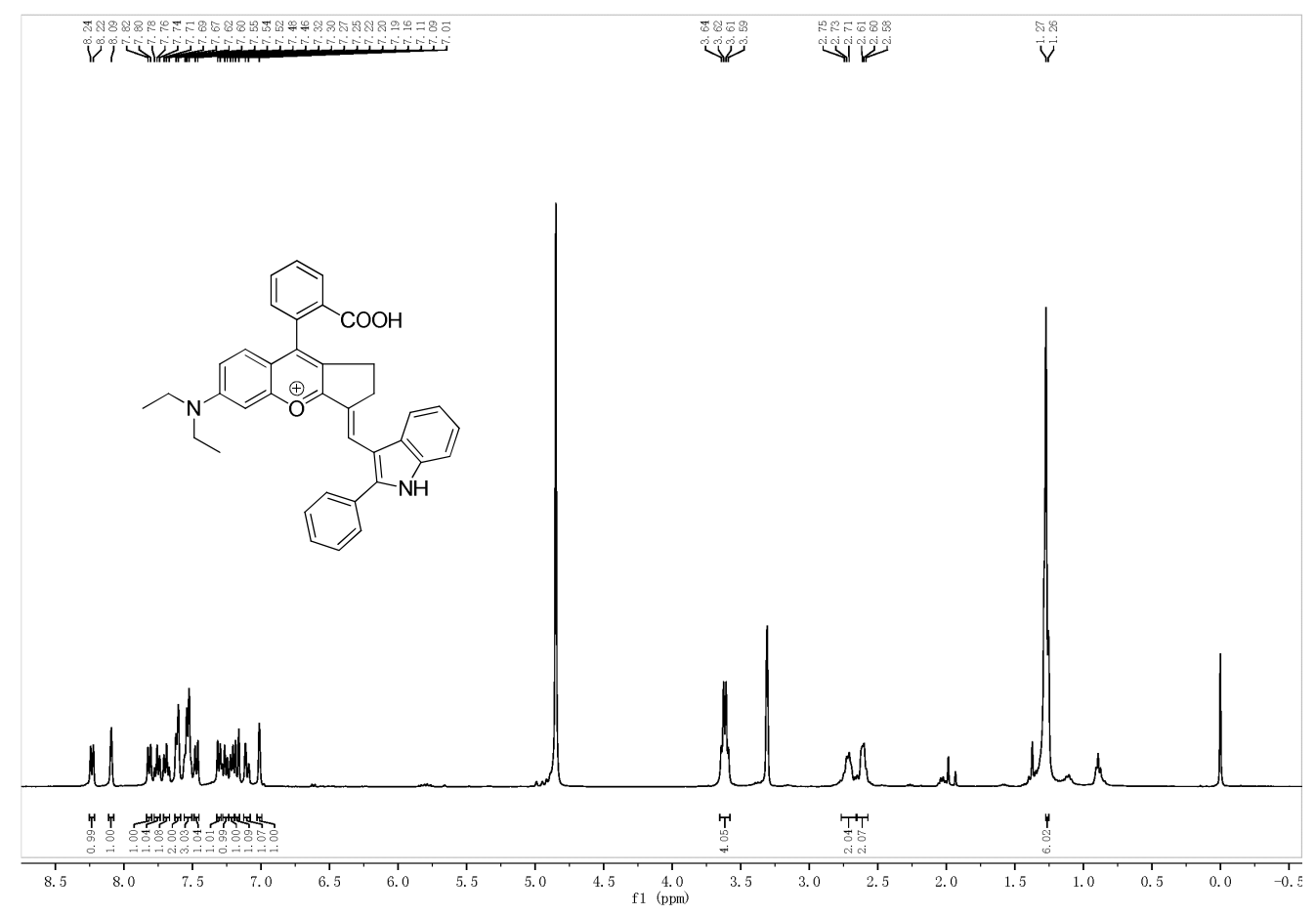

${ }^{1} \mathrm{H}$ NMR of CC26 in MeOD.

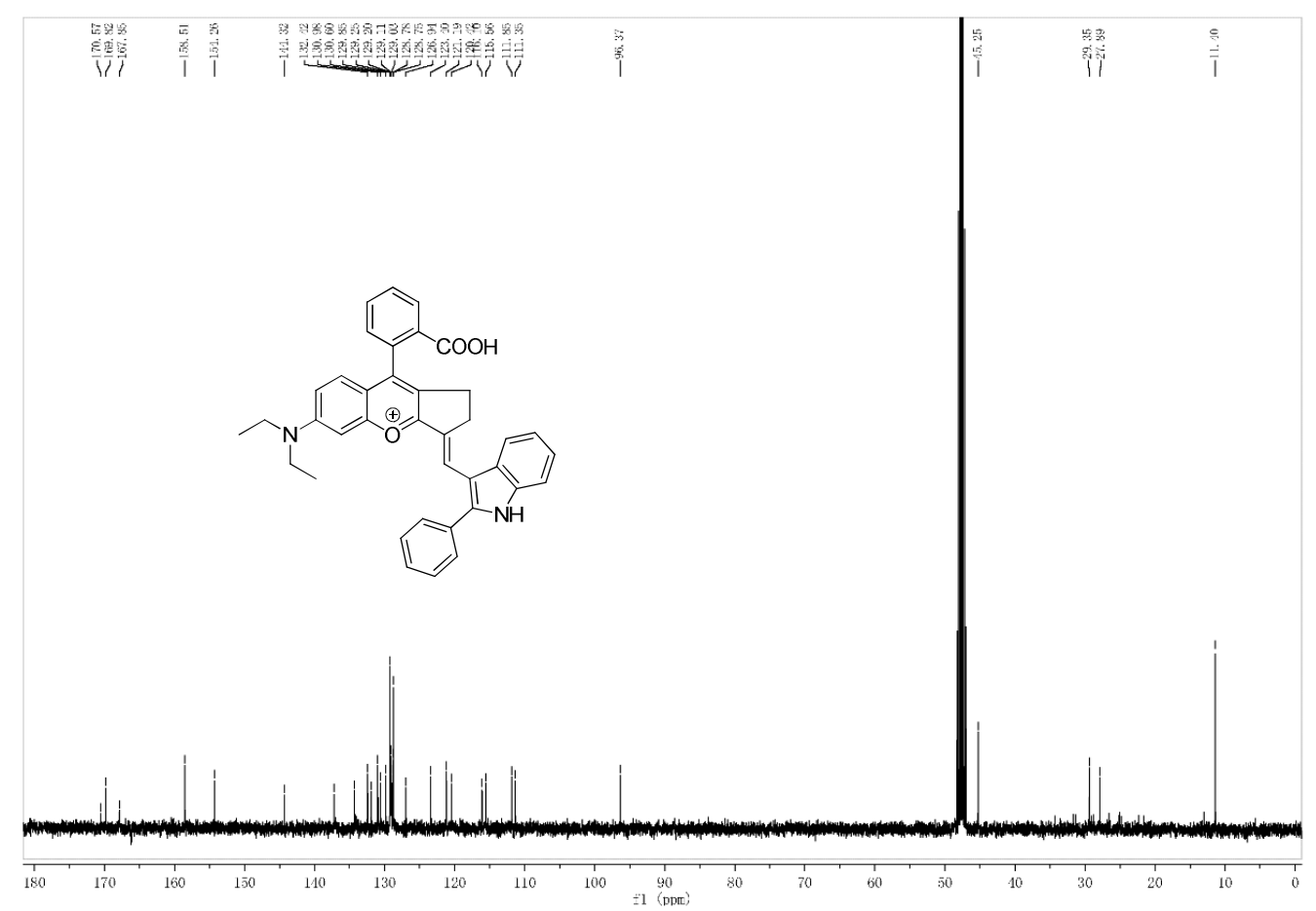

${ }^{13} \mathrm{C}$ NMR of CC26 in MeOD. 


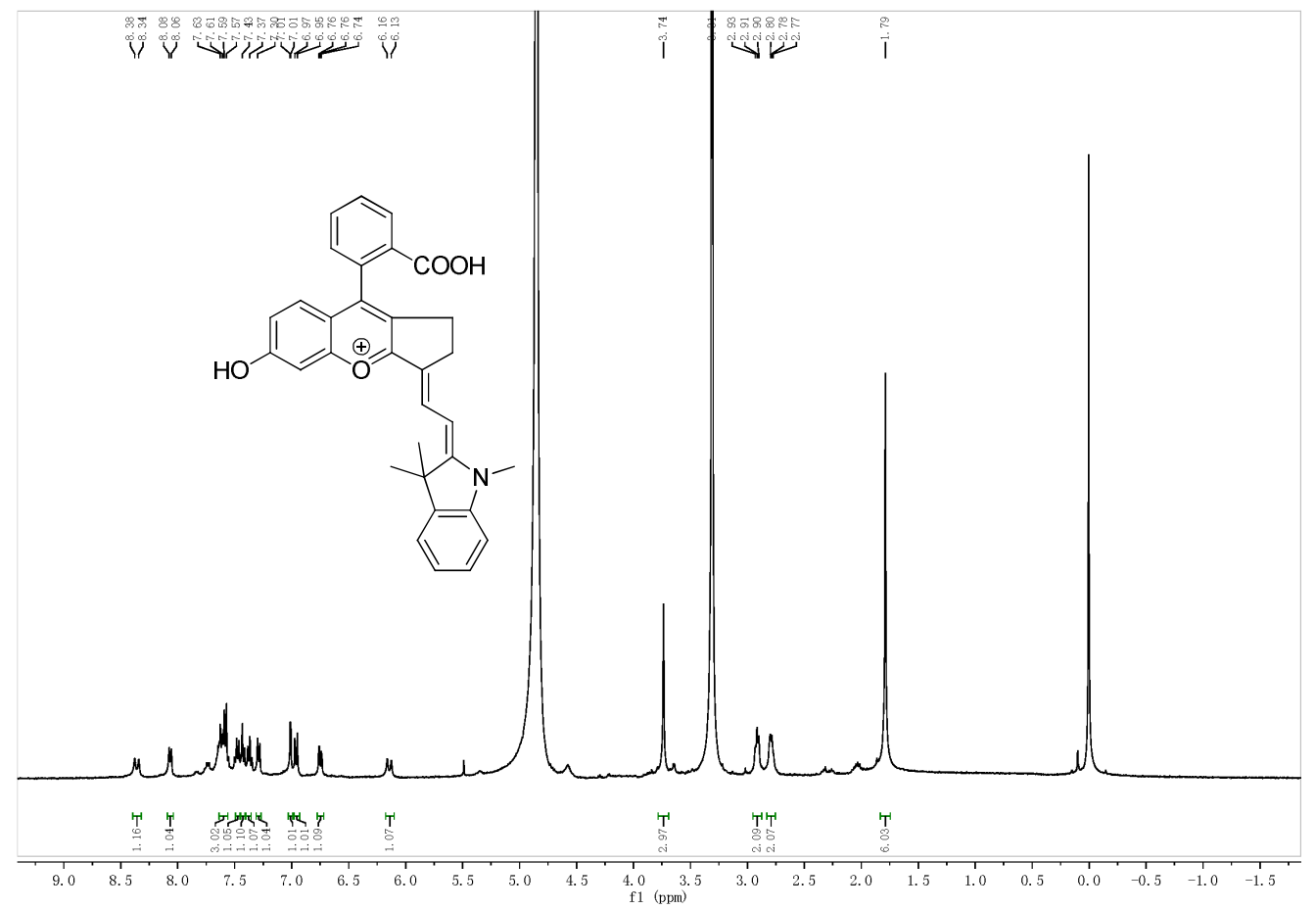

${ }^{1} \mathrm{H}$ NMR of CC33 in MeOD.
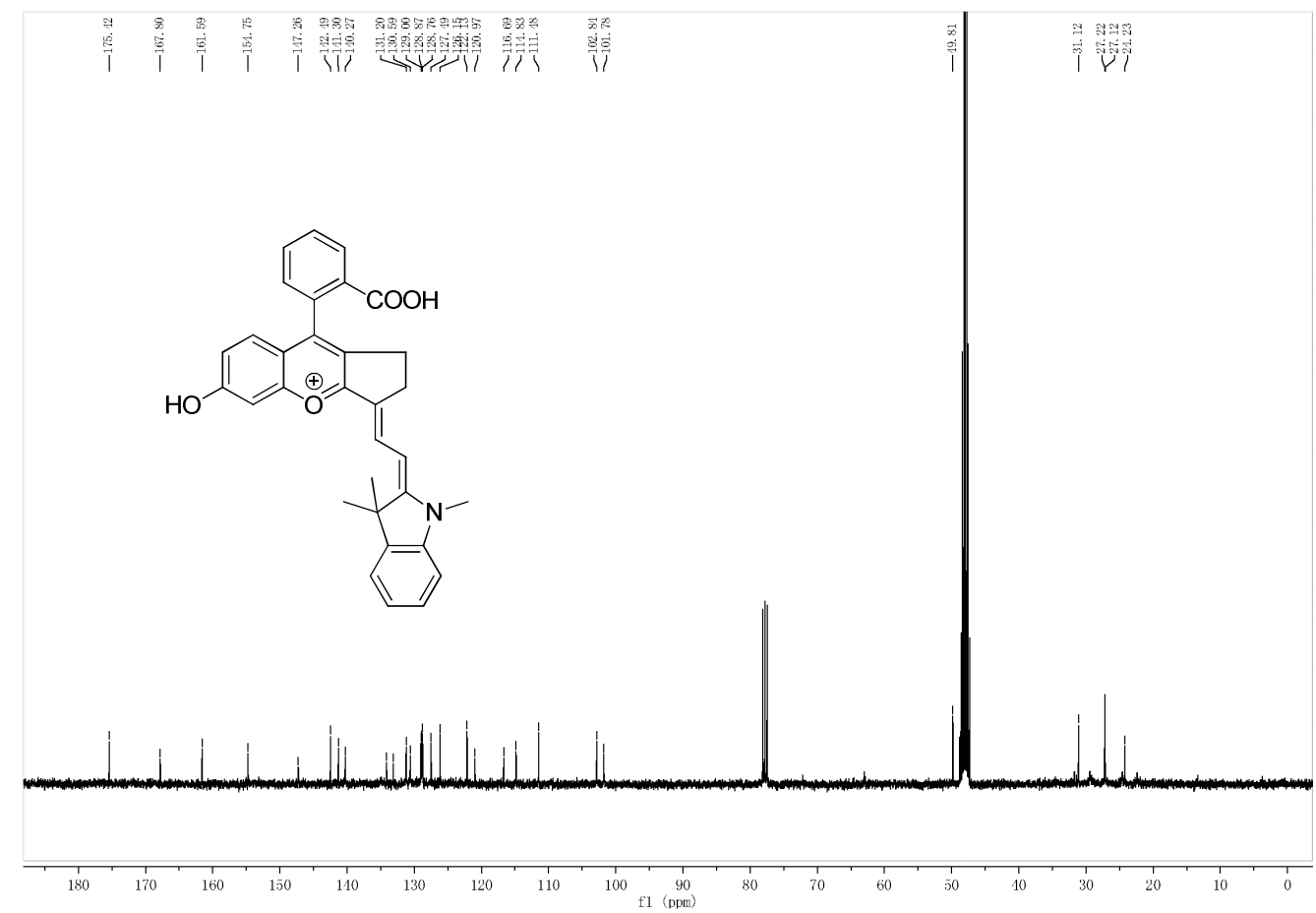

${ }^{33} \mathrm{C}$ NMR of $\mathbf{C C} 33$ in $\mathrm{MeOD} / \mathrm{CD}_{3} \mathrm{Cl}$. 


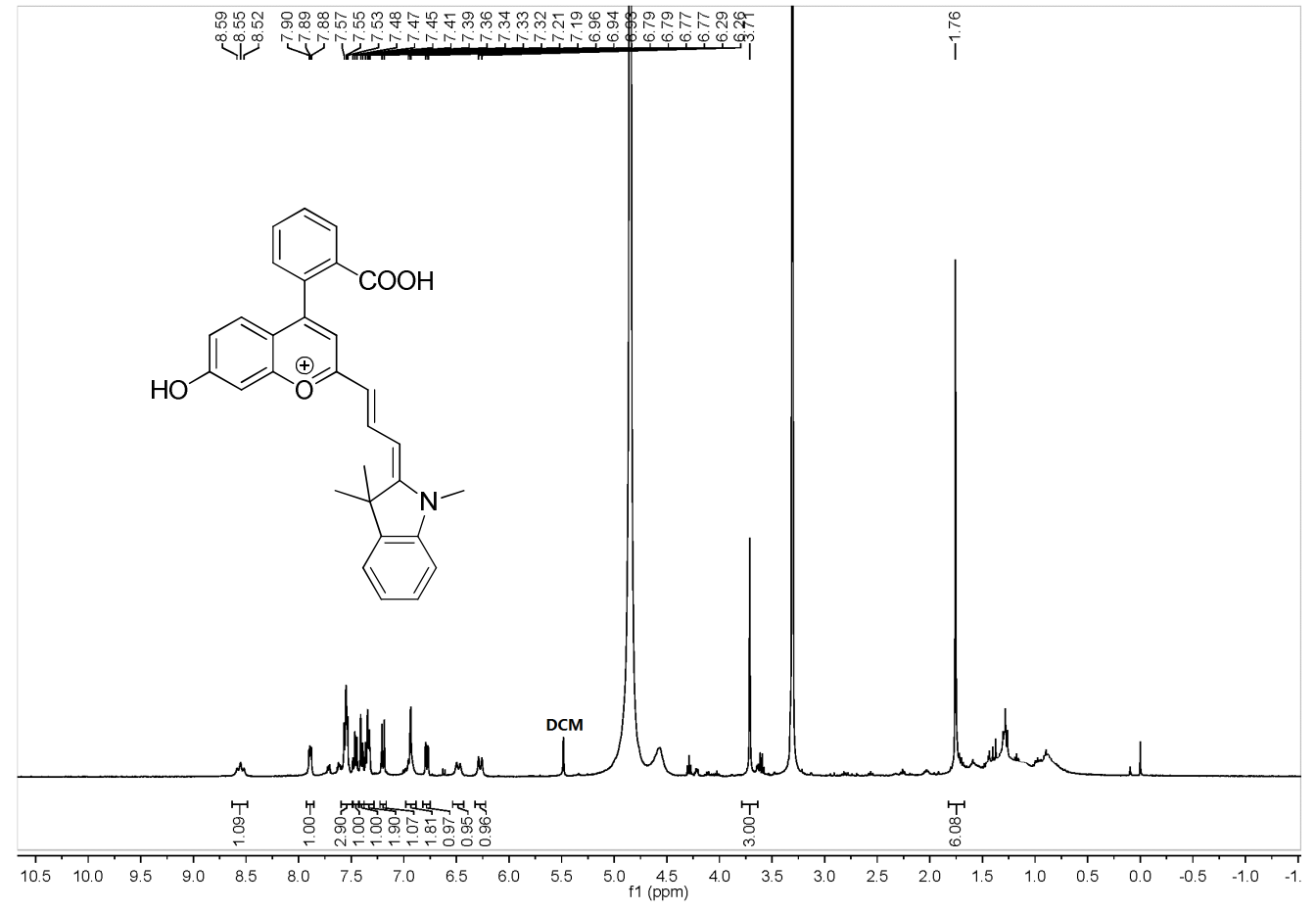

${ }^{1} \mathrm{H}$ NMR of CC34 in MeOD.

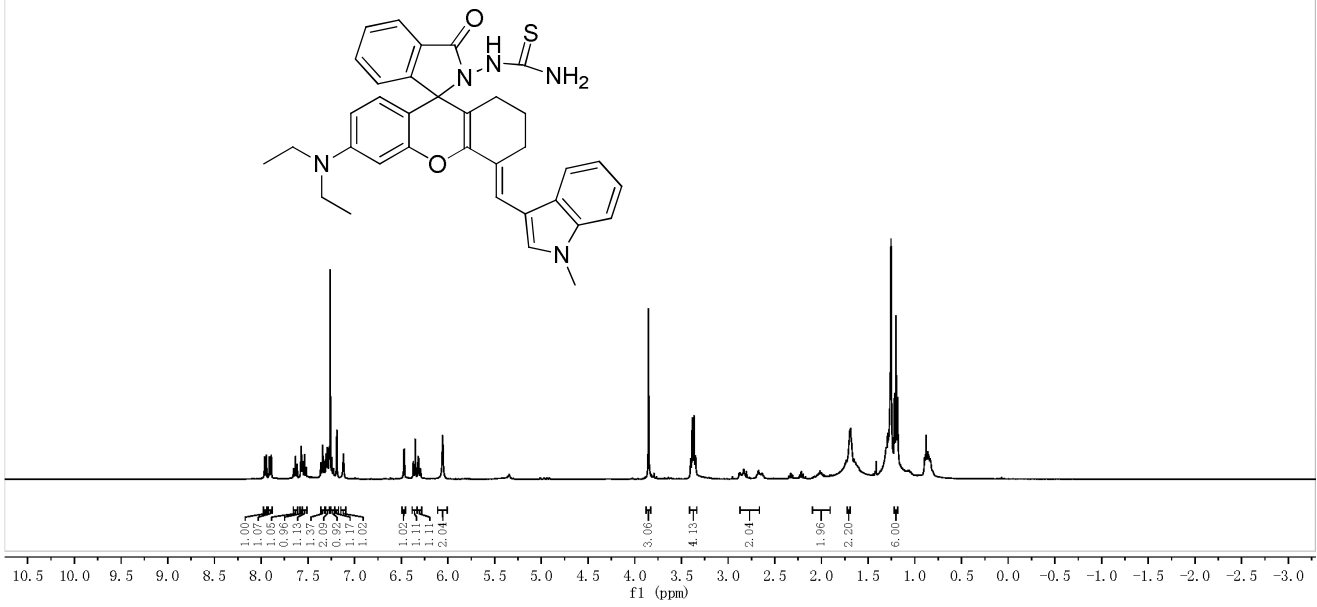

${ }^{1} \mathrm{H}$ NMR of $\mathbf{C C 3 5}$ in $\mathrm{CDCl}_{3}$. 


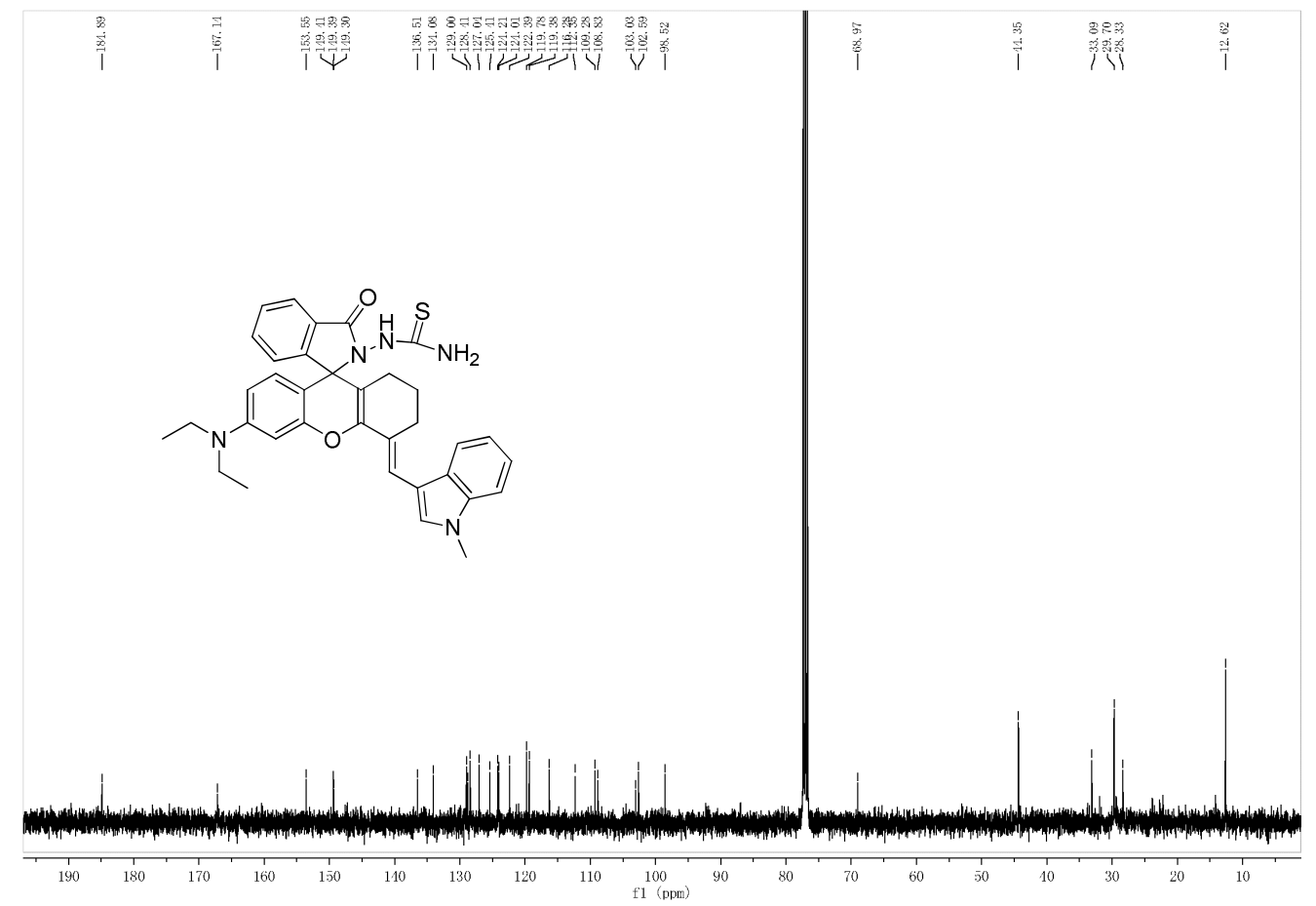

${ }^{13} \mathrm{C}$ NMR of $\mathbf{C C 3 5}$ in $\mathrm{CDCl}_{3}$. 